\title{
ECONOMICS
}

\section{Do We Really Know that U.S. Monetary Policy was Destabilizing in the 1970s?}

by

Qazi Haque,

Centre for Applied Macroeconomic Analysis and The University of Western Australia

Nicolas Groshenny

Centre for Applied Macroeconomic Analysis and The University of Adelaide

and

Mark Weder

Aarhus University and Centre for Applied

Macroeconomic Analysis 


\title{
Do We Really Know that U.S. Monetary Policy was Destabilizing in the 1970s?*
}

\author{
Qazi Haque $^{\dagger} \quad$ Nicolas Groshenny ${ }^{\ddagger} \quad$ Mark Weder ${ }^{\S}$
}

June 25, 2019

\begin{abstract}
The paper re-examines whether the Federal Reserve's monetary policy was a source of instability during the Great Inflation by estimating a sticky-price model with positive trend inflation, commodity price shocks and sluggish real wages. Our estimation provides empirical evidence for substantial wage-rigidity and finds that the Federal Reserve responded aggressively to inflation but negligibly to the output gap. In the presence of non-trivial real imperfections and well-identified commodity price-shocks, U.S. data prefers a determinate version of the New Keynesian model: monetary policy-induced indeterminacy and sunspots were not causes of macroeconomic instability during the pre-Volcker era.
\end{abstract}

*The authors are grateful to Gianni Amisano, Guido Ascari, Drago Bergholt, Hilde Bjørnland, Giovanni Caggiano, Fabio Canova, Efrem Castelnuovo, Ferre De Graeve, Chris Edmond, Yunjong Eo, Andrea Ferrero, Ippei Fujiwara, Francesco Furlanetto, Pedro Gomis-Porqueras, Punnoose Jacob, Frederic Karame, Benjamin Keen, Mariano Kulish, François Langot, Thomas Lubik, James Morley, Adrian Pagan, Luca Pensieroso, Petr Sedláček, Harald Uhlig and Raf Wouters for helpful comments on various drafts of this article. This work was supported with supercomputing resources provided by the Phoenix HPC service at The University of Adelaide. Weder acknowledges generous support from the Australian Research Council, under the grant DP140102869, as well as from the Bank of Finland and Keio University for their hospitality. Haque acknowledges generous support from the Australian Research Council, under the grant DP170100697, as well as the University of Oxford for their hospitality. JEL codes E32, E52, E58. Keywords: Trend inflation, Monetary policy, Great Inflation, Cost-push shocks, Indeterminacy, Wage sluggishnes, Sequential Monte Carlo algorithm.

${ }^{\dagger}$ CAMA and The University of Western Australia. qazi.haque@uwa.edu.au

${ }^{\ddagger}$ CAMA and The University of Adelaide. nicolas.groshenny@adelaide.edu.au

$\S$ Aarhus University and CAMA. mweder@econ.au.dk (corresponding author) 


\section{Introduction}

The Great Inflation was one of the defining macroeconomic chapters of the twentieth century. From the late 1960s and throughout the 1970s, the U.S. economy experienced both turbulent business cycle fluctuations as well as unprecedented high and volatile rates of inflation. By 1979 inflation hovered above 15 percent. Since the seminal works by Clarida et al. (2000) and Lubik and Schorfheide (2004), a dominant narrative of this historical episode attributes the macroeconomic fluctuations and elevated inflation to poorly designed monetary policy: the Federal Reserve's weak response to inflation generated equilibrium multiplicity and the resulting instability and sunspot shocks nourished further inflation movements. On the other hand, Gordon (1977) and Blinder (1982), among others, have singled out cost-push shocks - mainly arising from spikes in the prices of food and oil - as the principal causes of the 1970s' stagflation. ${ }^{1}$ Such cost-push shocks are largely absent from the more recent studies of the Great Inflation that focus on the interplay of monetary policy and indeterminacy.

This paper aims to re-examine these two views by estimating a sticky-price model to which we add three key factors that are often put forward as distinctive features of the Great Inflation period: positive trend inflation (Coibion and Gorodnichenko, 2011, and Ascari and Sbordone, 2014), commodity price shocks and real wage rigidity (Blanchard and Galí, 2010, and Blanchard and Riggi, 2013). In this version of a Generalized New Keynesian (GNK) economy, commodity price disturbances and wage rigidity generate a strong negative correlation between inflation and the output gap, thereby confronting the monetary authority with a difficult trade-off. ${ }^{2}$ This trade-off is important as it explains why our estimates of the Taylor rule parameters - in particular, a very weak response to the output gap and strong response to inflation and output growth - are different from the ones obtained by other studies of the Great Inflation. As in Hirose et al. (2017), we employ Bayesian techniques featuring the Sequential Monte Carlo (SMC) sampling algorithm of Herbst and Schorfheide (2014) to uncover the posterior distribution of the model's parameters over the entire

\footnotetext{
${ }^{1}$ See also Blinder and Rudd (2012) for a recent resurrection of this line of thought and Barsky and Kilian (2001) for a critical evaluation.

${ }^{2}$ Following Ascari and Sbordone (2014), we use the term GNK to refer to the New Keynesian model loglinearized around a positive steady-state inflation rate.
} 
parameter space. ${ }^{3}$ This upgrade is particularly relevant given the discontinuity that arises in the posterior distribution along the boundary between the determinacy and indeterminacy regions of the model. We estimate the artificial economy using quarterly observations on six key macroeconomic variables that are essential to properly identify cost-push shocks and their propagation as well as wage dynamics.

Our central claim is that we can rule out indeterminacy as a source of instability during the Great Inflation period. The underlying mechanism to this result is connected to monetary policy, in particular to the central bank's response to inflation and the output gap, as well as to the degree of wage sluggishness. We also take into account positive trend inflation as it alters the dynamics of the GNK model and makes price-setting firms more forward-looking, which effectively flattens the Phillips Curve. This flattening changes the parametric region of indeterminacy. As a result, adhering to the Taylor Principle is no longer sufficient to rule out indeterminacy. Moreover, weak responses of nominal interest rate setting to output gap variations and strong responses to output growth stabilize the economy (see Ascari and Ropele, 2009, and Coibion and Gorodnichenko, 2011). In fact, these upshots conjoin to our estimated Taylor Rule for the Pre-Volcker period: it is active with respect to inflation as in Hirose et al. (2017) but, at the same time, it entails a weaker response to the output gap and a stronger one to output growth. Our interpretation is that the central bank's response reflects the aforementioned trade-off between inflation and output gap stabilization in the presence of oil price shocks. An important element for this trade-off is a certain degree of real wage rigidity, a factor that has also been found important for understanding other macroeconomic puzzles. ${ }^{4}$ Along these lines, we make two contributions. First, we provide new theoretical insight regarding how wage sluggishness dampens the effect of trend inflation on equilibrium instability. Second, in the context of our estimated model, we find evidence for high degree of rigidity once we use wage data to identify wage dynamics. Then the estimated Tay-

\footnotetext{
${ }^{3}$ See also Ascari et al. (2019) for a different approach to estimation using SMC that relies on particle learning.

${ }^{4}$ See, for example, Barsky et al. (2015), Blanchard and Galí (2010), Blanchard and Riggi (2013), Hall (2005), Jeanne (1990), Michaillat (2012) and Uhlig (2007). Beaudry and DiNardo (1991) and others find micro-evidence along these lines. However, Basu and House (2016) suggest that a considerable portion of this rigidity disappears when accounting for heterogeneity.
} 
lor Rule involves a more active response to inflation, a stronger response to output growth and a close to non-existent response to the output gap. This combination is key for our determinacy result during the Pre-Volcker era.

When we estimate our model over the Great Moderation period, the interest rate responses to inflation and output growth almost double, while trend inflation falls considerably. These patterns are consistent with the findings of Coibion and Gorodnichenko (2011) and Hirose et al. (2017). We also find that the Federal Reserve moved its focus away from responding to headline inflation toward core inflation (Mehra and Sawhney, 2010), implying a less contractionary response of monetary policy to oil price shocks. Finally, wages became more flexible during the Great Moderation period and therefore oil price shocks were no longer as stagflationary as in the 1970s, which is in line with Blanchard and Gali's (2010) hypothesis as to why the 2000s are so different from the 1970s.

Our paper stands in line with Lubik and Schorfheide (2004) who, while building on Clarida at al. (2000), were the first to estimate a small-scale model with price frictions to find that the Federal Reserve's passive response to inflation resulted in sunspot equilibria in the 1970s. ${ }^{5}$ Hirose et al.'s (2017) study takes into consideration the role of positive trend inflation in a small-scale sticky-price model and, like Coibion and Gorodnichenko (2011), they show that the Federal Reserve's policy still induced sunspot equilibria. ${ }^{6}$ All of these existing empirical investigations of the link between monetary policy and equilibrium stability have sidestepped the explicit treatment of commodity price fluctuations and the policy trade-off that these disturbances can generate. Nicolò (2018) estimates a medium-scale model with cost push shocks similar to Smets and Wouters (2007) but abstracts from trend inflation. In addition, we also model commodity price shocks in a more explicit way which allows us to use particular observables that sharpen their identification. There are several studies of oil's role from a general equilibrium perspective. Natal (2012) considers an alternative mechanism to real wage rigidity through which oil price shocks can create a policy trade-off. His approach relies on the interaction between monopolistic competition

\footnotetext{
${ }^{5}$ Ascari et al. (2019) take an alternative path that involves temporarily explosive paths.

${ }^{6}$ Arias et al. (2019) work off a medium-scale model with trend inflation but only estimate the Great Moderation period.
} 
and the substitutability of oil. Nakov and Pescatori (2010) and Bjørnland et al. (2018) study the role of oil in driving the Great Moderation. Lastly, Blanchard and Riggi (2013) and Bodenstein et al. (2008) also examine the role of wage stickiness in the presence of oil price disturbances. More concretely, the former examines structural changes in the economy that have modified the transmission mechanism of oil shocks and the ladder addresses optimal monetary policy design in the presence of commodity price shocks. Thus, neither of these papers has examined whether or not monetary policy was a source of indeterminate equilibria and, therefore, instability during the Great Inflation.

\section{Model}

The artificial economy is a GNK model with a commodity product that we interpret as oil. ${ }^{7}$ The economy consists of monopolistically competitive wholesale firms that produce differentiated goods using labor and oil. These goods are bought by perfectly competitive firms (retailers) that weld them together into the final good that can be consumed. People rent out their labor services and labor markets are characterized by wage rigidity. Firms and households are price takers on the market for oil.

\subsection{People}

The economy is populated by a representative agent whose preferences over consumption $C_{t}$ and hours worked $N_{t}$ are ordered by

$$
E_{0} \sum_{t=0}^{\infty} \beta^{t} d_{t}\left[\ln \left(C_{t}-h \widetilde{C}_{t-1}\right)-\nu_{t} \frac{N_{t}^{1+\varphi}}{1+\varphi}\right]
$$

where $E_{t}$ is the expectations operator conditioned on time $t$ information, $\beta$ represents the discount factor, $h \widetilde{C}_{t-1}$ is external habit in consumption taken as exogenous by the agent where $0 \leq h<1$, and $\varphi$ is the inverse of the Frisch labor supply elasticity. Disturbances to the discount factor are denoted by preference shocks $d_{t}$ while $\nu_{t}$ stands for shocks to the disutility of labor. Both disturbances follow $\operatorname{AR}(1)$ processes:

$$
\ln d_{t}=\rho_{d} \ln d_{t-1}+\epsilon_{d, t}
$$

\footnotetext{
${ }^{7}$ The economy boils down to a variant of Blanchard and Galí (2010) when approximated around a zero inflation steady state. The Appendix provides details of the model.
} 
and

$$
\ln \nu_{t}=\rho_{\nu} \ln \nu_{t-1}+\epsilon_{\nu, t}
$$

Here $\epsilon_{d, t}$ and $\epsilon_{\nu, t}$ are independently and identically distributed, $N\left(0, \sigma_{d}^{2}\right)$ and $N\left(0, \sigma_{v}^{2}\right)$ respectively. Consumption is a Cobb-Douglas basket of domestically produced goods $C_{q, t}$ and imported oil $C_{m, t}$

$$
C_{t}=\Theta_{\chi} C_{m, t}^{\chi} C_{q, t}^{1-\chi} \quad 0 \leq \chi<1, \Theta_{\chi} \equiv \chi^{-\chi}(1-\chi)^{-(1-\chi)}
$$

where $\chi$ is the elasticity of oil in consumption. We denote the core consumer price index by $P_{q, t}$, the price of oil by $P_{m, t}$ and the headline consumer price index is then given by

$$
P_{c, t} \equiv P_{m, t}^{\chi} P_{q, t}^{1-\chi}
$$

People sell labor services to wholesale firms at the nominal wage $W_{t}$. They have access to a market for one-period riskless discount bonds $B_{t}$ at the interest rate $R_{t}$. All profits $\Pi_{t}$ flow back to households and the budget constraint in period $t$ is given by

$$
W_{t} N_{t}+B_{t-1}+\Pi_{t} \geq P_{q, t} C_{q, t}+P_{m, t} C_{m, t}+\frac{B_{t}}{R_{t}}
$$

Then, the agent's first-order conditions imply

$$
\frac{d_{t}}{P_{c, t}\left(C_{t}-h C_{t-1}\right)}=\beta E_{t} \frac{R_{t} d_{t+1}}{P_{c, t+1}\left(C_{t+1}-h C_{t}\right)}
$$

and

$$
\frac{W_{t}}{P_{c, t}}=\nu_{t} N_{t}^{\varphi}\left(C_{t}-h C_{t-1}\right)
$$

\section{$2.2 \quad$ Firms}

Two kinds of firms exist. Perfectly competitive final good firms produce the homogenous good $Q_{t}$ by choosing a combination of intermediate inputs $Q_{t}(i)$ subject to a Constant Elasticity of Substitution production technology. With $P_{q, t}(i)$ as the price of the intermediate good $i$ and $\varepsilon$ as the elasticity of substitution between any two differentiated goods, the demand for good $i$ is given by

$$
Q_{t}(i)=\left(\frac{P_{q, t}(i)}{P_{q, t}}\right)^{-\varepsilon} Q_{t} .
$$


There is a continuum of intermediate goods producers using labor $N_{t}$ and (imported) oil $M_{t}$. Each firm $i$ produces according to the production function

$$
Q_{t}(i)=M_{t}(i)^{\alpha}\left[A_{t} N_{t}(i)\right]^{1-\alpha} \quad 0 \leq \alpha<1
$$

in which $\alpha$ is the share of oil in production and $A_{t}$ denotes non-stationary laboraugmenting technology that follows

$$
\ln A_{t}=\bar{g}+\ln A_{t-1}+\epsilon_{g, t}
$$

Here, $\bar{g}$ stands for the steady-state gross rate of technological change and $\epsilon_{g, t}$ is independently and identically distributed $N\left(0, \sigma_{g}^{2}\right)$. Cost minimization implies that the firm's demand for oil is

$$
M_{t}(i)=\frac{\alpha}{\mathcal{M}_{t}^{P}(i)} \frac{Q_{t}(i)}{s_{t}} \frac{P_{q, t}(i)}{P_{q, t}}
$$

where $\mathcal{M}_{t}^{P}(i)$ is the firm's gross markup of price over marginal cost and $s_{t} \equiv \frac{P_{m, t}}{P_{q, t}}$ is the real price of oil which follows

$$
\ln s_{t}=\rho_{s} \ln s_{t-1}+\epsilon_{s, t}
$$

with $\epsilon_{s, t}$ independently and identically distributed $N\left(0, \sigma_{s}^{2}\right)$. Aggregating over all $i$ and defining $\Delta_{t} \equiv \int_{0}^{1}\left(\frac{P_{q, t}(i)}{P_{q, t}}\right)^{-\varepsilon} d i$ as the measure of relative price dispersion, (4) becomes

$$
M_{t}=\frac{\alpha}{\mathcal{M}_{t}^{P}} \frac{Q_{t}}{s_{t}} \Delta_{t}^{\frac{\varepsilon-1}{\varepsilon}}
$$

where the average gross markup is $\mathcal{M}_{t}^{P} \equiv \int_{0}^{1} \mathcal{M}_{t}^{P}(i) d i$. Next, combining the cost minimization condition and the production function yields the factor price frontier:

$$
\left(\frac{W_{t}}{P_{c, t}}\right)^{1-\alpha} \mathcal{M}_{t}^{P}=\mathcal{C} A_{t}^{1-\alpha} s_{t}^{-\alpha-\chi(1-\alpha)} \Delta_{t}^{-\frac{1}{\varepsilon}}
$$

where $\mathcal{C}$ is a constant that depends on $\alpha$ and $\chi$. The intermediate goods producers face a constant probability $0<1-\xi<1$ of being able to adjust prices to $P_{q, t}^{*}(i)$ to maximize expected discounted profits

$$
E_{t} \sum_{j=0}^{\infty} \xi^{j} \Lambda_{t, t+j}\left[\frac{P_{q, t}^{*}(i)}{P_{q, t+j}} Q_{t+j}(i)-\frac{W_{t+j}}{(1-\alpha) P_{q, t+j} A_{t+j}^{1-\alpha}}\left(\frac{(1-\alpha) P_{m, t+j}}{\alpha W_{t+j}}\right)^{\alpha} Q_{t+j}(i)\right]
$$


subject to the demand schedule (3) where $\Lambda_{t, t+j}$ is the stochastic discount factor. The first-order condition for the relative price $p_{q, t}^{*}(i) \equiv \frac{P_{q, t}^{*}(i)}{P_{q, t}}$ is

$$
p_{q, t}^{*}(i)=\frac{\varepsilon}{(\varepsilon-1)(1-\alpha)} \frac{E_{t} \sum_{j=0}^{\infty} \xi^{j} \Lambda_{t, t+j} \frac{W_{t+j}}{P_{q, t+j} A_{t+j}^{1-\alpha}}\left[\frac{(1-\alpha) P_{m, t+j}}{\alpha W_{t+j}}\right]^{\alpha}\left[\frac{P_{q, t}}{P_{q, t+j}}\right]^{-\varepsilon} Q_{t+j}}{E_{t} \sum_{j=0}^{\infty} \xi^{j} \Lambda_{t, t+j}\left[\frac{P_{q, t}}{P_{q, t+j}}\right]^{1-\varepsilon} Q_{t+j}} .
$$

Finally, the condition that trade is balanced yields a relation between aggregate consumption $C_{t}$, gross output $Q_{t}$ and gross domestic product $Y_{t}$ :

$$
P_{c, t} C_{t}=P_{q, t} Q_{t}-P_{m, t} M_{t}=\left(1-\frac{\alpha}{\mathcal{M}_{t}^{P}} \Delta_{t}^{\frac{\varepsilon-1}{\varepsilon}}\right) P_{q, t} Q_{t}=P_{y, t} Y_{t}
$$

where $P_{y, t}$ is the GDP deflator implicitly defined by

$$
P_{q, t} \equiv\left(P_{y, t}\right)^{1-\alpha}\left(P_{m, t}\right)^{\alpha} .
$$

\subsection{Monetary policy}

The central bank adjusts the short-term nominal interest rate $R_{t}$ according to the Taylor-type rule

$$
\frac{R_{t}}{\bar{R}}=\left(\frac{R_{t-1}}{\bar{R}}\right)^{\rho_{R}}\left(\left[\left(\frac{\pi_{c, t}}{\bar{\pi}}\right)^{\tau}\left(\frac{\pi_{q, t}}{\bar{\pi}}\right)^{1-\tau}\right]^{\psi_{\pi}}\left[\frac{Y_{t}}{Y_{t}^{*}}\right]^{\psi_{x}}\left[\frac{Y_{t} / Y_{t-1}}{\bar{g}}\right]^{\psi_{g}}\right)^{1-\rho_{R}} e^{\epsilon_{R, t}} .
$$

Here $\bar{R}$ is the steady state gross nominal interest rate and $\bar{\pi}$ denotes the central bank's inflation target (which is also the steady state level of inflation, i.e. trend inflation). Mehra and Sawhney (2010) suggest that the Federal Reserve used different inflation measures to inform policy decisions. In the model, this translates into the central bank responding to a convex combination of headline and core inflation rates governed by the weight $0 \leq \tau \leq 1$. The coefficients $\psi_{\pi}, \psi_{x}$ and $\psi_{g}$ dictate the central bank's response to the inflation gap, output gap and output growth respectively. Following Blanchard and Galí (2007) and Blanchard and Riggi (2013), the output gap here measures the deviation of actual GDP from its efficient level $Y_{t}^{*}$, defined as the allocation under flexible prices and perfect competition in goods and labor markets. ${ }^{8}$ The policy rule further allows for interest rate smoothing via $0 \leq \rho_{R}<1$. Policy shocks $\epsilon_{R, t}$ are independently and identically distributed $N\left(0, \sigma_{R}^{2}\right)$.

\footnotetext{
${ }^{8}$ Blanchard and Riggi (2013) point out that in a model with real wage rigidities, the flexible-price output gap may fluctuate a lot with respect to oil price changes. In contrast, the welfare-relevant output gap moves much less, follows more of a smooth time trend, and it appears to be what the Federal Reserves looks at.
} 


\subsection{Real wage sluggishness}

Departing from the above, we allow for real wage rigidities. Such rigidities have been found to be important in understanding the macroeconomic effect of oil price shocks (Blanchard and Galí, 2010, and Blanchard and Riggi, 2013), news shocks (Barsky et al., 2015), the behavior of labor markets (Hall, 2005, Michaillat, 2012) and asset markets (Uhlig, 2007) and the propagation of monetary policy shocks (Jeanne, 1990). We follow these insights and let wages adjust only partially, representing frictions not explicitly considered here. As pointed out by Blanchard and Galí (2007), this parsimonious formulation of wage rigidity entails micro-founded makeups without the need to confine to a particular one. Wage sluggishness modifies the intratemporal optimality condition (2) to

$$
\frac{W_{t}}{P_{c, t}}=\left(\frac{W_{t-1}}{P_{c, t-1}}\right)^{\gamma}\left(\nu_{t} N_{t}^{\varphi}\left(C_{t}-h C_{t-1}\right)\right)^{1-\gamma} \quad 0 \leq \gamma<1
$$

where $\gamma$ determines the degree of rigidity, which will be a key parameter in the estimation. This modification looks after the possibility that model estimations with a flexible wage specification ascribe wage dynamics to shocks when instead those dynamics are more accurately modelled as frictions. That is, we let the data decide and if it prefers the original micro-founded specification, the estimation procedure remains free to select a value of $\gamma$ close to zero.

\subsection{Equilibrium dynamics}

New Keynesian models are prone to indeterminacy and this is particularly the case in versions with trend inflation. Real wage rigidity affects the dynamic properties of the economy as well. To show this, Figure 1 plots the indeterminacy regions of the linearized model in the $\psi_{\pi}-\gamma$ space for various levels of trend inflation. ${ }^{9}$ In the absence of any real wage rigidity, i.e. $\gamma=0$, the minimum responsiveness to inflation required to generate determinacy rises with trend inflation. Ascari and Ropele (2009) show that trend inflation makes price-setting firms more forward-looking which then flattens the New Keynesian Phillips Curve (in the inflation-marginal costs plane).

\footnotetext{
${ }^{9}$ When constructing Figure 1, the policy rule is $\widehat{R}_{t}=\psi_{\pi} \widehat{\pi}_{t}$ and parameters are set at $\beta=0.99$, $\varepsilon=11, \xi=0.75, \varphi=1, h=0$ and $\alpha=\chi=0$.
} 
Therefore, the central bank needs to respond more strongly to inflation in order to generate a reduction in output that would generate a given reduction in inflation. You can see this expansion of the indeterminacy region to the right in Figure 1. Real wage rigidity partially undoes this effect and the minimum responsiveness to inflation $\psi_{\pi}$ required for equilibrium uniqueness decreases. In the figure the impact of wage rigidity on indeterminacy translates into a downwardly sloping boundary. The intuition goes as follows. Assume a sudden increase in inflation expectations that usually sets off sunspot events. In the standard New Keynesian model, ruling out these self-fulfilling expectations requires the central bank to increase the shortrun rate to drive up the real interest rate - the Taylor Principle. This then contracts output and lowers inflation, and therefore sunspot beliefs are no longer consistent in equilibrium. With trend inflation and a flatter Phillips Curve, the central bank is required to be more aggressive to keep indeterminacy in check. However, in a model with real wage rigidity, there is an additional channel at play, namely the endogenous increase in wage markup. As the real interest rate goes up, the wage markup (defined as the ratio of real wages to the marginal rate of substitution) increases endogenously due to the sluggish adjustment of real wages. An increase in wage markup reduces aggregate employment and therefore aggregate output and inflation. As a result, the central bank does not need to respond to inflation as strongly as otherwise it would have to in the absence of real wage rigidity. ${ }^{10}$

\section{Model solution and econometric strategy}

To solve the rational expectations system with indeterminacy, we follow the methodology of Lubik and Schorfheide (2003). The full set of solutions to the linear rational expectations model under indeterminacy entails the system of transition equations

$$
\varrho_{t}=\Phi(\theta) \varrho_{t-1}+\Phi_{\varepsilon}(\theta, \widetilde{M}) \varepsilon_{t}+\Phi_{\zeta}(\theta) \zeta_{t}
$$

where $\varrho_{t}$ is the vector of endogenous variables, $\theta$ is the vector of the model's parameters, $\varepsilon_{t}$ is the vector of fundamental shocks, and $\Phi(\theta), \Phi_{\varepsilon}(\theta, \widetilde{M})$ and $\Phi_{\zeta}(\theta)$ are appropriately defined coefficient matrices. ${ }^{11}$ Indeterminacy alters the solution in two

\footnotetext{
${ }^{10}$ If trend inflation is zero, Araújo's (2009) result of no effect of real wage rigidity holds.

${ }^{11}$ Under determinacy, the solution boils down to a VAR, i.e. $\varrho_{t}=\Phi^{D}(\theta) \varrho_{t-1}+\Phi_{\varepsilon}^{D}(\theta) \varepsilon_{t}$.
} 


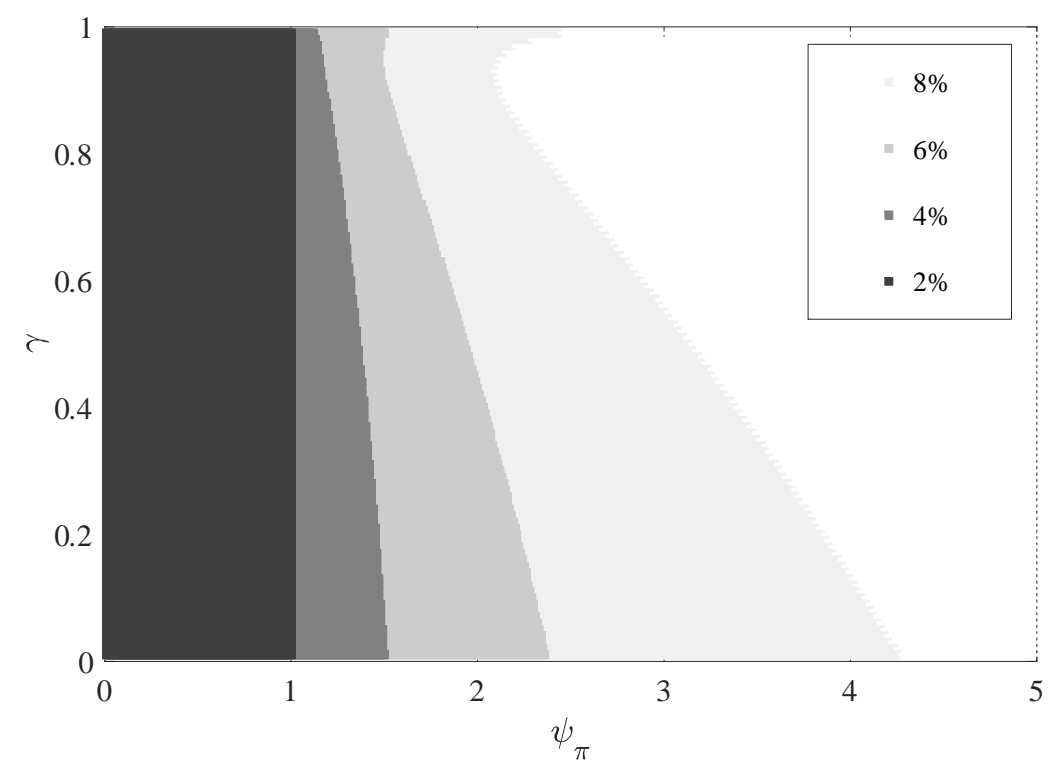

Figure 1: Indeterminacy zones (shaded)

distinct ways. First, purely extrinsic disturbances, i.e. the sunspots $\zeta_{t}$, hit the economy. These sunspot shocks satisfy $\zeta_{t} \sim$ i.i.d. $\mathbf{N}\left(0, \sigma_{\zeta}^{2}\right)$. Second, the propagation of fundamental shocks is no longer uniquely pinned down and this multiplicity is captured by the (arbitrary) elements of $\widetilde{M}$. Following Lubik and Schorfheide (2004), we replace $\widetilde{M}$ with $M^{*}(\theta)+M$ and set the prior mean for $M$ equal to zero in the subsequent empirical analysis. This strategy selects $M^{*}(\theta)$ such that the responses of the endogenous variables to fundamental shocks are continuous at the boundary between the determinacy and the indeterminacy regions. Analytical solution for the boundary in the current model is infeasible. We therefore resort to a numerical procedure to find the boundary by perturbing the parameter $\psi_{\pi}$ in the monetary policy rule. ${ }^{12}$ In Section 8.3, we will present the robustness of our results with regards to alternative perturbations.

\subsection{Bayesian estimation with the Sequential Monte Carlo algorithm}

We use Bayesian techniques to estimate the model parameters and to test for indeterminacy using posterior model probabilities. We follow Hirose et al. (2017) by

\footnotetext{
${ }^{12}$ See also Hirose (2014) as well as Justiniano and Primiceri (2008).
} 
employing the Sequential Monte Carlo algorithm of Herbst and Schorfheide (2014) to produce an accurate approximation of the posterior distribution. ${ }^{13}$ In models like ours that contain determinacy and indeterminacy regions, the likelihood function is susceptible to exhibit multiple modes and a discontinuity at the parametric boundary. These irregularities prove to be a challenge for standard Markov chain Monte Carlo techniques (such as the Random Walk Metropolis Hastings algorithm) and these standard techniques often fail to explore the entire parameter space. The SMC algorithm circumvents this problem by building a sequence of posterior distributions through steadily tempering the likelihood function. Accordingly, we are able to estimate the model simultaneously over the determinacy and indeterminacy regions. ${ }^{14}$ The likelihood function is given by

$$
p\left(\mathbf{X}_{T} \mid \theta_{S}, S\right)=1\left\{\theta_{S} \in \Theta^{D}\right\} p^{D}\left(\mathbf{X}_{T} \mid \theta_{D}, D\right)+1\left\{\theta_{S} \in \Theta^{I}\right\} p^{I}\left(\mathbf{X}_{T} \mid \theta_{I}, I\right) .
$$

Here, $\theta_{S}$ stands for the parameters of model $S . \Theta^{D}, \Theta^{I}$ are the determinacy and indeterminacy regions of the parameter space, $1\left\{\theta_{S} \in \Theta^{S}\right\}$ is the indicator function that equals 1 if $\theta_{S} \in \Theta^{S}$ and zero otherwise where $S \in\{D, I\} . \mathbf{X}_{T}$ denotes observations through period $T$ and $p^{D}\left(\mathbf{X}_{T} \mid \theta_{D}, D\right)$ and $p^{I}\left(\mathbf{X}_{T} \mid \theta_{I}, I\right)$ are the likelihood functions under determinacy and indeterminacy. The SMC algorithm constructs a particle approximation of the posterior distribution by building a sequence of tempered posteriors defined as

$$
\Pi_{n}\left(\theta_{S}\right)=\frac{\left[p\left(\mathbf{X}_{T} \mid \theta_{S}, S\right)\right]^{\phi_{n}} p\left(\theta_{S} \mid S\right)}{\int_{\theta_{S}}\left[p\left(\mathbf{X}_{T} \mid \theta_{S}, S\right)\right]^{\phi_{n}} p\left(\theta_{S} \mid S\right) d \theta_{S}}
$$

with $p\left(\mathbf{X}_{T} \mid \theta_{S}, S\right)$ denoting the likelihood function, $p\left(\theta_{S} \mid S\right)$ the prior density, and $\phi_{n}$ the tempering schedule that slowly increases from zero to one determined by

$$
\phi_{n}=\left(\frac{n-1}{N_{\phi}-1}\right)^{\delta}
$$

where $\delta$ controls the shape of the tempering schedule. The algorithm generates weighted draws from the sequence of posteriors $\left\{\Pi_{n}(\theta)\right\}_{n=1}^{N_{\phi}}$, where $N_{\phi}$ is the number of stages. At any stage, the posterior distribution is represented by a swarm of

\footnotetext{
${ }^{13}$ Farmer et al. (2015) and Bianchi and Nicolò (2019) use alternative strategies to estimate models with indeterminacy.

${ }^{14}$ Lubik and Schorfheide's (2004) test for indeterminacy separately estimates the model for each parametric region. In our application, we monitor that the SMC's exploration is indeed crossing the boundary between the regions.
} 
particles $\left\{\theta_{n}^{i}, W_{n}^{i}\right\}_{i=1}^{N}$, where $W_{n}^{i}$ is the weight associated with $\theta_{n}^{i}$ and $N$ denotes the number of particles. The algorithm involves three main steps. First, in the correction step, the particles are re-weighted to reflect the posterior density in iteration $n$. Next, in the selection step, any particle degeneracy is eliminated by resampling the particles. Liu and Chen (1998) propose a rule-of-thumb measure of this degeneracy as the reciprocal of the uncentered variance of the particles, called the effective sample size (ESS). We use systematic resampling whenever $E S S<\frac{N}{2}$. Finally, in the mutation step, the particles are propagated forward using a Markov transition kernel to adapt to the current bridge density by using one step of a single-block Random Walk Metropolis Hastings algorithm. In the first stage, i.e. when $n=1, \phi_{1}$ is zero and so the prior density serves as an efficient proposal density for $\Pi_{1}(\theta)$. Therefore, the algorithm is initialized by drawing the initial particles from the prior. The idea is that the density of $\Pi_{n}(\theta)$ may be a good proposal density for $\Pi_{n+1}(\theta)$. In our estimation, the tuning parameters $N, N_{\phi}$ and $\delta$ are fixed ex ante. We use $N=10000$ particles and $N_{\phi}=200$ stages and set $\delta$ at 2 following Herbst and Schorfheide (2015).

\subsection{Calibration}

We calibrate a subset of the model parameters to avoid identification issues. The discount factor $\beta$ is set to 0.99 , the steady state markup at ten percent, i.e. $\varepsilon=11$, and the inverse of the labor-supply elasticity to one. Following the computations in Blanchard and Galí (2010), we calibrate the shares of oil in production and consumption to $\alpha=0.015$ and $\chi=0.023$ for the first and $\alpha=0.012$ and $\chi=0.017$ for the second sample period. The autoregressive parameter of the commodity price shock is fixed at $\rho_{s}=0.995$ to model the commodity price being very close to a random walk (as in the data) yet retaining stationarity (Blanchard and Riggi, 2013).

\subsection{Prior distributions}

We estimate all remaining parameters. The specifications of the prior distributions are summarized in Table 1 and are in line with Smets and Wouters (2007) and Hirose et al. (2017). ${ }^{15}$ The prior for the parameter determining the central bank's

\footnotetext{
${ }^{15}$ The inverse gamma priors are of the form $p(\sigma \mid v, \varsigma) \infty \sigma^{-v-1} e^{-\frac{v \varsigma^{2}}{2 \sigma^{2}}}$ where $\nu=4$ and $\varsigma=0.38$ for all shocks but commodity prices. For commodity price shock $\varsigma=3.81$. The prior predictive
} 
responsiveness to inflation $\psi_{\pi}$ follows a gamma distribution centred at 1.10 with a standard deviation of 0.50 , while the response coefficients to both the output gap and output growth are centred at 0.125 with standard deviation 0.10. We use Beta distributions for the degree of interest rate smoothing $\rho_{R}$, the weight on headline inflation in the Taylor rule $\tau$, the Calvo probability $\xi$, the real wage rigidity $\gamma$, the habit persistence in consumption $h$, the persistence of the discount factor shock and the labor supply shock. For the standard deviations of the innovations, the priors for all but one follow an inverse-gamma distribution with mean 0.50 and standard deviation 0.20 . The exception is the standard deviation of the oil price shocks. We center its prior distribution at 5.00 with a standard deviation of 2.00 to account for the higher volatility of these disturbances. The priors of $M$ follow a standard normal distribution as in Lubik and Schorfheide (2004). Our choice of priors leads to a prior predictive probability of determinacy of 0.51 and indicates no prior bias toward either determinacy or indeterminacy.

\subsection{Data}

We estimate the model using quarterly observations on six aggregate U.S. variables. The vector of observables $X_{t}$ contains the quarterly growth rates of real percapita GDP $(G D P)$, the consumer price index $(C P I)$, the core consumer price index $($ Core $C P I)$, real wages and the level of the Federal Funds rate expressed in percent on a quarterly basis $(F F R)$. Justiniano et al. (2013) find that most high frequency variations of the wage series are measurement errors and argue that ignoring this fact may lead to erroneous inference. We follow their approach by matching the model's wage variable to two measures of hourly labor income, allowing for errors in their measurement, along the lines of Boivin and Giannoni (2006). ${ }^{16}$ Matching the model's wage to two measures of the return to labor improves the ability to isolate the high frequency idiosyncrasies specific to each series, from a common component that is more likely to represent genuine macroeconomic forces. Wage data are hourly compensation for the Nonfarm Business sector for all persons (NHC) and average hourly earnings of production and non-supervisory employees $(H E)$ which we both deflate

probability of determinacy is 0.51 .

${ }^{16}$ See also Doko Tchatoka et al. (2017). 
by the CPI to obtain measures for real wages. Then the measurement equation is

$$
X_{t}=\left[\begin{array}{c}
100 \Delta \log G D P_{t} \\
100 \Delta \log C P I_{t} \\
100 \Delta \log C o r e C P I_{t} \\
F F R_{t} \\
100 \Delta \log \left(N H C_{t} / C P I_{t}\right) \\
100 \Delta \log \left(H E_{t} / C P I_{t}\right)
\end{array}\right]=\left[\begin{array}{c}
g^{*} \\
\pi^{*} \\
\pi^{*} \\
R^{*} \\
g^{*} \\
g^{*}
\end{array}\right]+\left[\begin{array}{cc}
\mathbf{I}_{4} & \mathbf{O} \\
\mathbf{O} & \mathbf{\Lambda} \\
2 \times 4 &
\end{array}\right]\left[\begin{array}{c}
\widehat{g}_{y, t} \\
\widehat{\pi}_{c, t} \\
\widehat{\pi}_{q, t} \\
\widehat{R}_{t} \\
\widehat{g}_{w, t} \\
\widehat{g}_{w, t}
\end{array}\right]+\left[\begin{array}{c}
\mathbf{0} \\
4 \times 1 \\
\mathbf{e}_{t}
\end{array}\right]
$$

where $g^{*}=100(\bar{g}-1)$ is the quarterly steady-state net output growth rate, $\pi^{*}=$ $100(\bar{\pi}-1)$ is the steady-state net inflation rate and $R^{*}=100(\bar{R}-1)$ stands for the steady-state net interest rate. Furthermore, $\widehat{g}_{y, t}$ denotes the growth rate of output, $\widehat{\pi}_{c, t}$ is consumer price inflation, $\widehat{\pi}_{q, t}$ is core consumer price inflation, $\widehat{g}_{w, t}$ is the growth rate of real wages and $\widehat{R}_{t}$ denotes the nominal interest rate. Hatted variables stand for $\log$ deviations from the steady state. $\boldsymbol{\Lambda}=\operatorname{diag}(1, \lambda)$ is a $2 \times 2$ diagonal matrix of factor loadings relating the latent model concept of real wage growth to the two indicators and $\mathbf{e}_{t}=\left[e_{N H C, t}, e_{H E, t}\right]^{\prime} \sim i . i . d .(\mathbf{0}, \boldsymbol{\Sigma})$ is a vector of serially and mutually uncorrelated indicator-specific measurement errors, with $\boldsymbol{\Sigma}=\operatorname{diag}\left(\sigma_{N H C}^{2}, \sigma_{H E}^{2}\right)$. We jointly estimate the parameters $(\boldsymbol{\Lambda}, \boldsymbol{\Sigma})$ of the measurement equation along with the structural parameters. Our prior distributions for the loadings and measurement errors are $\lambda \sim N(1.00,0.50)$ and $\sigma_{N H C}^{2}, \sigma_{H E}^{2} \sim I G(0.10,0.20)$. The estimation is conducted over two sample periods: 1966:I to 1979:II and 1984:I to 2008:II. This separation aligns with the monetary policy literature as it looks at the pre-Volcker and the Great Moderation periods individually. We exclude the years of the Volcker disinflation as in Lubik and Schorfheide (2004). We do not demean or detrend any series.

\section{Was U.S. monetary policy destabilizing in the 1970s?}

We find that the answer is no. Table 2 reports the marginal data densities of our estimated model as well as the posterior probabilities of determinacy for both sample periods. ${ }^{17}$ The posterior probability of determinacy is calculated as the fraction

\footnotetext{
17 The SMC algorithm delivers a numerical appoximation of the marginal data density as a byproduct in the correction step (see Herbst and Schorfheide, 2015).
} 
Table 1: Prior Distributions and Posterior Parameter Estimates

\begin{tabular}{|c|c|c|c|c|}
\hline Name & Density & $\begin{array}{l}\text { Prior Mean } \\
\text { (std. dev.) }\end{array}$ & $\begin{array}{l}\text { Posterior Mean (pre-1979) } \\
\text { [90\% interval] }\end{array}$ & $\begin{array}{l}\text { Posterior Mean (post-1984) } \\
{[90 \% \text { interval] }}\end{array}$ \\
\hline$\psi_{\pi}$ & Gamma & $\begin{array}{l}1.10 \\
(0.50)\end{array}$ & $\begin{array}{c}1.51 \\
{[1.25,1.78]}\end{array}$ & $\begin{array}{c}3.09 \\
{[2.50,3.66]}\end{array}$ \\
\hline$\psi_{x}$ & Gamma & $\begin{array}{l}0.125 \\
(0.10)\end{array}$ & $\begin{array}{c}0.03 \\
{[0.00,0.07]}\end{array}$ & $\begin{array}{c}0.11 \\
{[0.03,0.20]}\end{array}$ \\
\hline$\psi_{g}$ & Gamma & $\begin{array}{c}0.125 \\
(0.10)\end{array}$ & $\begin{array}{c}0.33 \\
{[0.10,0.53]}\end{array}$ & $\begin{array}{c}0.62 \\
{[0.38,0.82]}\end{array}$ \\
\hline$\rho_{R}$ & Beta & $\begin{array}{l}0.50 \\
(0.20)\end{array}$ & $\begin{array}{c}0.68 \\
{[0.59,0.78]}\end{array}$ & $\begin{array}{c}0.73 \\
{[0.65,0.78]}\end{array}$ \\
\hline$\tau$ & Beta & $\begin{array}{l}0.50 \\
(0.20)\end{array}$ & $\begin{array}{c}0.58 \\
{[0.32,0.84]}\end{array}$ & $\begin{array}{c}0.14 \\
{[0.05,0.23]}\end{array}$ \\
\hline$\pi^{*}$ & Normal & $\begin{array}{l}1.00 \\
(0.50)\end{array}$ & $\begin{array}{l}1.37 \\
{[1.07,1.64]}\end{array}$ & $\begin{array}{c}0.97 \\
{[0.81,1.11]}\end{array}$ \\
\hline$R^{*}$ & Gamma & $\begin{array}{l}1.50 \\
(0.25)\end{array}$ & $\begin{array}{c}1.53 \\
{[1.19,1.85]}\end{array}$ & $\begin{array}{l}1.46 \\
{[1.24,1.71]}\end{array}$ \\
\hline$g^{*}$ & Normal & $\begin{array}{l}0.50 \\
(0.10)\end{array}$ & $\begin{array}{c}0.45 \\
{[0.34,0.57]}\end{array}$ & $\begin{array}{c}0.17 \\
{[0.11,0.26]}\end{array}$ \\
\hline$\xi$ & Beta & $\begin{array}{l}0.50 \\
(0.05)\end{array}$ & $\begin{array}{c}0.60 \\
{[0.53,0.66]}\end{array}$ & $\begin{array}{c}0.61 \\
{[0.54,0.67]}\end{array}$ \\
\hline$\gamma$ & Beta & $\begin{array}{l}0.50 \\
(0.20)\end{array}$ & $\begin{array}{c}0.89 \\
{[0.83,0.94]}\end{array}$ & $\begin{array}{c}0.46 \\
{[0.26,0.63]}\end{array}$ \\
\hline$h$ & Beta & $\begin{array}{l}0.50 \\
(0.10)\end{array}$ & $\begin{array}{c}0.38 \\
{[0.28,0.50]}\end{array}$ & $\begin{array}{c}0.24 \\
{[0.16,0.33]}\end{array}$ \\
\hline$\rho_{d}$ & Beta & $\begin{array}{l}0.70 \\
(0.10)\end{array}$ & $\begin{array}{c}0.76 \\
{[0.66,0.86]}\end{array}$ & $\begin{array}{c}0.84 \\
{[0.78,0.90]}\end{array}$ \\
\hline$\rho_{\nu}$ & Beta & $\begin{array}{l}0.70 \\
(0.10)\end{array}$ & $\begin{array}{c}0.86 \\
{[0.74,0.97]}\end{array}$ & $\begin{array}{c}0.99 \\
{[0.97,0.99]}\end{array}$ \\
\hline$\sigma_{s}$ & Inv-Gamma & $\begin{array}{l}5.00 \\
(2.00)\end{array}$ & $\begin{array}{c}17.31 \\
{[14.60,20.00]}\end{array}$ & $\begin{array}{c}20.14 \\
{[17.79,22.31]}\end{array}$ \\
\hline$\sigma_{g}$ & Inv-Gamma & $\begin{array}{l}0.50 \\
(0.20)\end{array}$ & $\begin{array}{c}0.49 \\
{[0.35,0.64]}\end{array}$ & $\begin{array}{c}0.43 \\
{[0.31,0.54]}\end{array}$ \\
\hline$\sigma_{r}$ & Inv-Gamma & $\begin{array}{l}0.50 \\
(0.20)\end{array}$ & $\begin{array}{c}0.30 \\
{[0.25,0.36]}\end{array}$ & $\begin{array}{c}0.17 \\
{[0.15,0.20]}\end{array}$ \\
\hline$\sigma_{d}$ & Inv-Gamma & $\begin{array}{l}0.50 \\
(0.20)\end{array}$ & $\begin{array}{c}1.84 \\
{[1.33,2.37]}\end{array}$ & $\begin{array}{c}1.21 \\
{[0.90,1.47]}\end{array}$ \\
\hline$\sigma_{\nu}$ & Inv-Gamma & $\begin{array}{l}0.50 \\
(0.20)\end{array}$ & $\begin{array}{c}0.38 \\
{[0.25,0.49]}\end{array}$ & $\begin{array}{c}0.74 \\
{[0.53,0.98]}\end{array}$ \\
\hline$\sigma_{\zeta}$ & Inv-Gamma & $\begin{array}{l}0.50 \\
(0.20)\end{array}$ & $\begin{array}{c}0.44 \\
{[0.21,0.68]}\end{array}$ & $\begin{array}{c}0.47 \\
{[0.22,0.73]}\end{array}$ \\
\hline$M_{s, \zeta}$ & Normal & $\begin{array}{l}0.00 \\
(1.00)\end{array}$ & $\begin{array}{c}-0.01 \\
{[-1.55,1.67]}\end{array}$ & $\begin{array}{c}-0.10 \\
{[-1.80,1.50]}\end{array}$ \\
\hline$M_{g, \zeta}$ & Normal & $\begin{array}{l}0.00 \\
(1.00)\end{array}$ & $\begin{array}{c}0.00 \\
{[-1.54,1.68]}\end{array}$ & $\begin{array}{c}-0.11 \\
{[-1.73,1.39]}\end{array}$ \\
\hline$M_{r, \zeta}$ & Normal & $\begin{array}{l}0.00 \\
(1.00)\end{array}$ & $\begin{array}{c}0.01 \\
{[-1.57,1.62]}\end{array}$ & $\begin{array}{c}0.03 \\
{[-1.59,1.60]}\end{array}$ \\
\hline$M_{d, \zeta}$ & Normal & $\begin{array}{l}0.00 \\
(1.00)\end{array}$ & $\begin{array}{c}0.08 \\
{[-1.50,1.74]}\end{array}$ & $\begin{array}{c}0.06 \\
{[-1.49,1.70]}\end{array}$ \\
\hline$M_{\nu, \zeta}$ & Normal & $\begin{array}{l}0.00 \\
(1.00)\end{array}$ & $\begin{array}{c}0.01 \\
{[-1.60,1.64]}\end{array}$ & $\begin{array}{c}0.06 \\
{[-1.48,1.70]}\end{array}$ \\
\hline$\lambda$ & Normal & $\begin{array}{l}1.00 \\
(0.50)\end{array}$ & $\begin{array}{c}1.05 \\
{[0.66,1.43]}\end{array}$ & $\begin{array}{c}0.30 \\
{[0.16,0.43]}\end{array}$ \\
\hline$\sigma_{N H C}^{2}$ & Inv-Gamma & $\begin{array}{l}0.10 \\
(0.20)\end{array}$ & $\begin{array}{c}0.36 \\
{[0.19,0.51]}\end{array}$ & $\begin{array}{c}0.66 \\
{[0.55,0.77]}\end{array}$ \\
\hline$\sigma_{H E}^{2}$ & Inv-Gamma & $\begin{array}{l}0.10 \\
(0.20)\end{array}$ & $\begin{array}{c}0.47 \\
{[0.33,0.63]}\end{array}$ & $\begin{array}{c}0.38 \\
{[0.32,0.44]}\end{array}$ \\
\hline
\end{tabular}




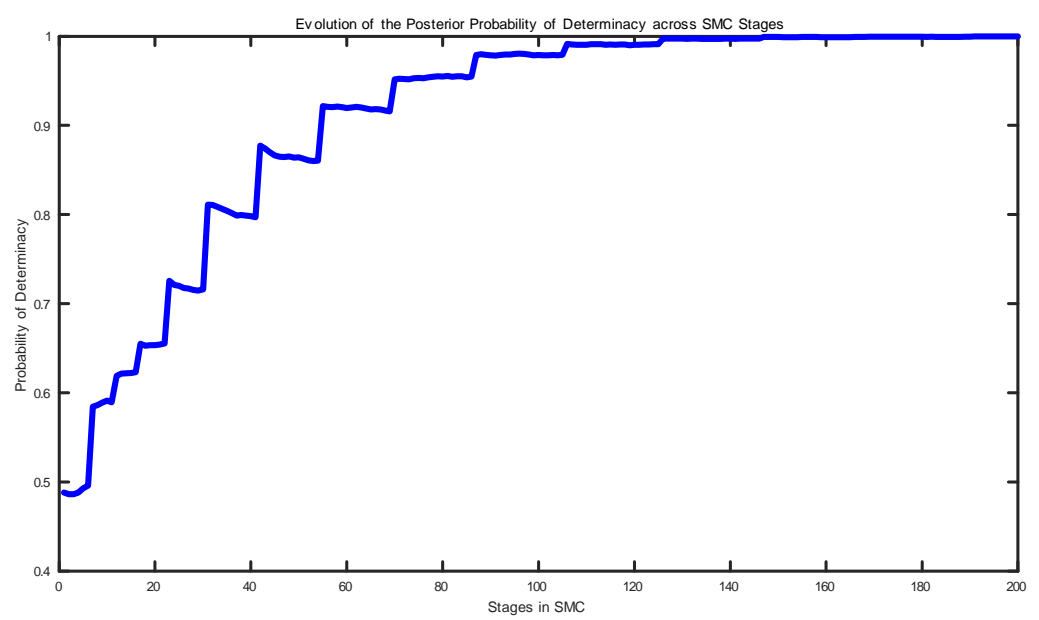

Figure 2: Evolution of the posterior probability. The estimation involves six observables and is performed for the 1966:I to 1979:II period.

of the draws in the final stage of the SMC algorithm that generate determinate equilibrium. The main result of our paper is that pre-Volcker monetary policy did not generate indeterminacy. Determinacy prevailed in the turbulent 1970s as well as during the Great Moderation. In each episode, the posterior distribution puts all its mass in the determinacy region. Figure 2 plots the evolution of the posterior probability of determinacy across the 200 stages of the SMC algorithm for the preVolcker period. ${ }^{18}$ As the particles are re-weighted and their values modified at each stage, this tempering of the likelihood function gradually moves the approximation to the posterior distribution from its prior level towards the probability that is reported in the first row of Table 2. This finding differs strikingly from Lubik and Schorfheide (2004), Hirose et al. (2017) and Nicolò (2018).

\subsection{What drove determinacy?}

Our diagnosis of the Seventies may be surprising and a natural question that arises is: what drove it? To shed light on this issue, the fourth column in Table 1 reports the posterior means and 90 percent highest posterior density intervals for the pre-Volcker period, based on 10000 particles from the final importance sampling. Let us focus on the monetary policy parameters first. The steady-state annualized inflation rate

\footnotetext{
${ }^{18}$ Note that in the first stage, the prior probability of determinacy is around 0.5 in line with our priors such that a-priori the test is unbiased.
} 
Table 2: Determinacy versus Indeterminacy

\begin{tabular}{lcc}
\hline \hline & Log-data density & Probability of determinacy \\
\hline 1966:I-1979:II & -279.27 & 1 \\
& & 1 \\
1984:I-2008:II & -275.71 & 1 \\
\hline \hline
\end{tabular}

Notes: According to the prior distributions, the probability of determinacy is 0.51 .

is around 5.5 percent during this period. The response to inflation was active, i.e. greater than one, which echoes Orphanides (2004) and parallels Hirose et al. (2017). However, our estimated interest rate reactions to the output gap and to output growth differ from Hirose et al. (2017). In particular, we find that the Federal Reserve was barely responding to output gap fluctuations and that it was instead reacting strongly to output growth. As shown by Coibion and Gorodnichenko (2011), these two features tend to stabilize GNK economies. In fact, the combination of a strong response to inflation together with an insignificant reaction to the output gap holds the key to our result that the US economy was likely in the determinacy region even during the 1970s.

To connect with existing work and better understand which features of our econometric strategy lead to our interpretation of the Great Inflation, we now consider a sequence of special cases of our empirical model and report the findings in Tables 3 and 4 . To begin with, we shut down oil in the model by calibrating the shares of oil in consumption and production to zero $(\alpha=\chi=0)$. The model then features only one concept of inflation and we therefore set the weight of headline inflation in the policy rule equal to one $(\tau=1)$. We further set the degree of real wage rigidity to zero $(\gamma=0)$ and turn off the labor supply disturbances. This artificial economy thus boils down to a simple GNK model with positive trend inflation and three fundamental shocks (discount factor, technology and monetary policy) similar to Hirose et al. (2017). We estimate this specification using only three standard observables: output growth, the Federal Funds rate and inflation (Headline CPI). The first row in Table 3 confirms that the estimation favors the models's indeterminate version in the preVolcker period, although we obtain a somewhat lower probability of indeterminacy 
Table 3: Determinacy versus Indeterminacy (1966:I - 1979:II)

\begin{tabular}{|c|c|c|}
\hline & Log density & Prob. of det. \\
\hline GNK, 3 obs $\left(g_{y, t}, R_{t}, \pi_{c, t}\right)[\alpha, \chi, \gamma=0 ; \tau=1]$ & -118.02 & 0.07 \\
\hline GNK, 3 obs $\left(g_{y, t}, R_{t}, \pi_{c, t}\right)[\alpha, \chi=0 ; \tau=1]$ & -118.90 & 0.20 \\
\hline GNK with Oil, 3 obs $\left(g_{y, t}, R_{t}, \pi_{c, t}\right)[\tau=1]$ & -118.22 & 0 \\
\hline GNK with Oil, 4 obs $\left(g_{y, t}, R_{t}, \pi_{c, t}, \pi_{q, t}\right)$ & -157.12 & 0.80 \\
\hline GNK with Oil, 6 obs $\left(g_{y, t}, R_{t}, \pi_{c, t}, \pi_{q, t}, \Delta w_{t}^{N H C}, \Delta w_{t}^{H E}\right)$ & -279.27 & 1 \\
\hline
\end{tabular}

Notes: The state-space models are (from top to bottom): i) Basic GNK model estimated with three observables; ii) GNK model featuring wage rigidity estimated with three observables; iii) GNK model with oil and wage rigidity estimated with three observables; iv) GNK with oil and wage rigidity estimated with four observables (i.e. two inflation measures); v) GNK with oil and wage rigidity estimated with six observables (i.e. two wage series). Parameters in square brackets are calibrated. "obs" denotes the number of observables which are indicated in parentheses.

than Hirose et al. (2017). ${ }^{19}$

Having bridged the gap with existing studies, we now sequentially add one feature at a time until we end up again with our original model. To begin with, we introduce real wage rigidity by specifying an agnostic prior Beta $(0.5,0.2)$ for $\gamma$ and we estimate this model with only three observables. You can see from the third column in Table 4 that the degree of real wage rigidity is not properly identified and the posterior distiribution of $\gamma$ is similar to the prior. The posterior probability of determinacy increases slightly to 20 percent (second row of Table 3). This finding is consistent with our previous discussion regarding how real wage rigidity affects the determinacy region (see Figure 1).

We then turn on oil by resetting the values of $\alpha$ and $\chi$ to their benchmark calibrations. This setup gives us a New Keynesian model with sluggish wages and micro-founded cost-push shocks, features that are reminiscent of the environment in the 1970s, yet are missing in existing empirical investigations on indeterminacy. We

\footnotetext{
${ }^{19}$ Our model also features homogenous labor (as in Ascari and Sbordone, 2014), while Hirose et al. (2017) assume firm-specific labor. Moreover, they use a different measure of inflation (GDP deflator) to estimate their model.
} 
also switch on labor supply disturbances. For now, we continue to use only three observables in the estimation (hence we calibrate $\tau$ at one). The third row of Table 3 shows that data now strongly prefers indeterminacy for the pre-Volcker period. The decline in the posterior probability of determinacy reflects the lower wage rigidity that is obtained when we include persistent labor supply shocks. Looking at the fourth column in Table 4, we observe that the standard deviation of oil price shocks $\sigma_{s}$ is virtually indistinguishable from the prior suggesting identification issues: using only one inflation measure does not provide sufficient information to pin down commodity price shocks.

Hence, we next simultaneously treat both headline and core inflation as observables and our dataset now includes four variables. This step enables a tight identification of oil-price shocks or more generally commodity price shocks (see equation 1). We also estimate the weight $\tau$ in the policy rule as it can now be identified. The fourth row of Table 3 shows that the probability of determinacy rises considerably. Moreover, as anticipated, the innovation to the oil-price shock $\sigma_{s}$ is now well identified: the posterior mean is one order of magnitude larger than the prior mean.

The last step deals with the degree of wage sluggishness $\gamma$ which is a key parameter in our artificial economy. As Blanchard and Galí (2007) argue, the presence of real wage rigidity generates a trade-off between stabilizing inflation and the output gap in response to supply-side disturbances. Moreover, Blanchard and Riggi (2013) document that real wage rigidity plays a fundamental role in the propagation of oil price shocks. To sharpen the identification of this rigidity parameter, we next add real wage data, i.e. we employ all six observables to estimate the model. This step then gives us our benchmark setup again. As already argued above, the pre-Volcker period is then best characterized by determinacy and, as you can see in the sixth column of Table 4 , by a high degree of real wage rigidity.

Figure 3 shows the evolution of the dynamics in the $\psi_{\pi}-\psi_{x}$ space for four estimation setups for the pre-Volcker period. ${ }^{20}$ The panel in the North West corner represents the results from the basic GNK model estimated with the three standard observables (similar to Hirose et al. 2017), while our baseline results are visible in the

\footnotetext{
${ }^{20}$ We report specifications i), iii), iv) and v) from Table 3.
} 
Table 4: Parameter Estimates (1966:I-1979:II)

\begin{tabular}{|c|c|c|c|c|c|}
\hline & $\begin{array}{c}\text { GNK } \gamma=0 \\
3 \text { obs }\end{array}$ & $\begin{array}{l}\text { GNK } \\
3 \text { obs }\end{array}$ & $\begin{array}{c}\text { GNK-Oil } \\
3 \text { obs }\end{array}$ & $\begin{array}{c}\text { GNK-Oil } \\
4 \text { obs }\end{array}$ & $\begin{array}{c}\text { GNK-Oil } \\
6 \text { obs }\end{array}$ \\
\hline$\psi_{\pi}$ & $\begin{array}{c}0.96 \\
{[0.87,1.11]}\end{array}$ & $\begin{array}{c}0.96 \\
{[0.76,1.16]}\end{array}$ & $\begin{array}{c}0.94 \\
{[0.75,1.12]}\end{array}$ & $\begin{array}{c}1.16 \\
{[0.93,1.35]}\end{array}$ & $\begin{array}{c}1.51 \\
{[1.25,1.78]}\end{array}$ \\
\hline$\psi_{x}$ & $\begin{array}{c}0.10 \\
{[0.00,0.22]}\end{array}$ & $\begin{array}{c}0.14 \\
{[0.00,0.27]}\end{array}$ & $\begin{array}{c}0.23 \\
{[0.00,0.42]}\end{array}$ & $\begin{array}{c}0.15 \\
{[0.00,0.31]}\end{array}$ & $\begin{array}{c}0.03 \\
{[0.00,0.07]}\end{array}$ \\
\hline$\psi_{g}$ & $\begin{array}{c}0.09 \\
{[0.00,0.17]}\end{array}$ & $\begin{array}{c}0.11 \\
{[0.01,0.21]}\end{array}$ & $\begin{array}{c}0.11 \\
{[0.01,0.21]}\end{array}$ & $\begin{array}{c}0.14 \\
{[0.01,0.26]}\end{array}$ & $\begin{array}{c}0.33 \\
{[0.10,0.53]}\end{array}$ \\
\hline$\rho_{R}$ & $\begin{array}{c}0.41 \\
{[0.28,0.53]}\end{array}$ & $\begin{array}{c}0.44 \\
{[0.29,0.59]}\end{array}$ & $\begin{array}{c}0.48 \\
{[0.36,0.61]}\end{array}$ & $\begin{array}{c}0.50 \\
{[0.35,0.64]}\end{array}$ & $\begin{array}{c}0.68 \\
{[0.59,0.78]}\end{array}$ \\
\hline$\tau$ & 1 & 1 & 1 & $\begin{array}{c}0.65 \\
{[0.43,0.88]}\end{array}$ & $\begin{array}{c}0.58 \\
{[0.32,0.84]}\end{array}$ \\
\hline$\pi^{*}$ & $\begin{array}{c}1.40 \\
{[1.07,1.72]}\end{array}$ & $\begin{array}{c}1.43 \\
{[1.14,1.71]}\end{array}$ & $\begin{array}{c}1.34 \\
{[1.00,1.69]}\end{array}$ & $\begin{array}{c}1.38 \\
{[1.09,1.70]}\end{array}$ & $\begin{array}{c}1.37 \\
{[1.07,1.64]}\end{array}$ \\
\hline$R^{*}$ & $\begin{array}{c}1.54 \\
{[1.21,1.85]}\end{array}$ & $\begin{array}{c}1.57 \\
{[1.30,1.83]}\end{array}$ & $\begin{array}{c}1.50 \\
{[1.19,1.79]}\end{array}$ & $\begin{array}{c}1.55 \\
{[1.23,1.84]}\end{array}$ & $\begin{array}{c}1.53 \\
{[1.19,1.85]}\end{array}$ \\
\hline$g^{*}$ & $\begin{array}{c}0.46 \\
{[0.31,0.62]}\end{array}$ & $\begin{array}{c}0.49 \\
{[0.33,0.65]}\end{array}$ & $\begin{array}{c}0.51 \\
{[0.36,0.65]}\end{array}$ & $\begin{array}{c}0.51 \\
{[0.37,0.65]}\end{array}$ & $\begin{array}{c}0.45 \\
{[0.34,0.57]}\end{array}$ \\
\hline$\xi$ & $\begin{array}{c}0.50 \\
{[0.43,0.60]}\end{array}$ & $\begin{array}{c}0.50 \\
{[0.42,0.59]}\end{array}$ & $\begin{array}{c}0.54 \\
{[0.46,0.61]}\end{array}$ & $\begin{array}{c}0.57 \\
{[0.48,0.65]}\end{array}$ & $\begin{array}{c}0.60 \\
{[0.53,0.66]}\end{array}$ \\
\hline$\gamma$ & 0 & $\begin{array}{c}0.51 \\
{[0.17,0.90]}\end{array}$ & $\begin{array}{c}0.33 \\
{[0.07,0.60]}\end{array}$ & $\begin{array}{c}0.30 \\
{[0.04,0.59]}\end{array}$ & $\begin{array}{c}0.89 \\
{[0.83,0.94]}\end{array}$ \\
\hline$h$ & $\begin{array}{c}0.38 \\
{[0.27,0.48]}\end{array}$ & $\begin{array}{c}0.47 \\
{[0.28,0.51]}\end{array}$ & $\begin{array}{c}0.37 \\
{[0.27,0.49]}\end{array}$ & $\begin{array}{c}0.31 \\
{[0.21,0.41]}\end{array}$ & $\begin{array}{c}0.38 \\
{[0.28,0.50]}\end{array}$ \\
\hline$\rho_{d}$ & $\begin{array}{c}0.83 \\
{[0.73,0.92]}\end{array}$ & $\begin{array}{c}0.78 \\
{[0.65,0.90]}\end{array}$ & $\begin{array}{c}0.70 \\
{[0.54,0.86]}\end{array}$ & $\begin{array}{c}0.68 \\
{[0.53,0.83]}\end{array}$ & $\begin{array}{c}0.76 \\
{[0.66,0.86]}\end{array}$ \\
\hline$\rho_{\nu}$ & - & - & $\begin{array}{c}0.69 \\
{[0.53,0.86]}\end{array}$ & $\begin{array}{c}0.72 \\
{[0.56,0.87]}\end{array}$ & $\begin{array}{c}0.86 \\
{[0.74,0.97]}\end{array}$ \\
\hline$\sigma_{s}$ & - & - & $\begin{array}{c}5.43 \\
{[2.12,8.45]}\end{array}$ & $\begin{array}{c}17.03 \\
{[14.44,19.58]}\end{array}$ & $\begin{array}{c}17.31 \\
{[14.60,20.00]}\end{array}$ \\
\hline$\sigma_{g}$ & $\begin{array}{c}1.49 \\
{[1.17,1.80]}\end{array}$ & $\begin{array}{c}1.57 \\
{[1.19,1.93]}\end{array}$ & $\begin{array}{c}1.51 \\
{[1.17,1.86]}\end{array}$ & $\begin{array}{c}1.26 \\
{[0.95,1.73]}\end{array}$ & $\begin{array}{c}0.49 \\
{[0.35,0.64]}\end{array}$ \\
\hline$\sigma_{r}$ & $\begin{array}{c}0.32 \\
{[0.25,0.38]}\end{array}$ & $\begin{array}{c}0.31 \\
{[0.24,0.38]}\end{array}$ & $\begin{array}{c}0.30 \\
{[0.25,0.36]}\end{array}$ & $\begin{array}{c}0.31 \\
{[0.24,0.38]}\end{array}$ & $\begin{array}{c}0.30 \\
{[0.25,0.36]}\end{array}$ \\
\hline$\sigma_{d}$ & $\begin{array}{c}0.96 \\
{[0.76,1.16]}\end{array}$ & $\begin{array}{c}0.56 \\
{[0.31,0.85]}\end{array}$ & $\begin{array}{c}0.40 \\
{[0.20,0.60]}\end{array}$ & $\begin{array}{c}0.86 \\
{[0.35,1.31]}\end{array}$ & $\begin{array}{c}1.84 \\
{[1.33,2.37]}\end{array}$ \\
\hline$\sigma_{\nu}$ & - & - & $\begin{array}{c}0.36 \\
{[0.19,0.53]}\end{array}$ & $\begin{array}{c}0.45 \\
{[0.22,0.69]}\end{array}$ & $\begin{array}{c}0.38 \\
{[0.25,0.49]}\end{array}$ \\
\hline$\sigma_{\zeta}$ & $\begin{array}{c}0.53 \\
{[0.20,0.85]}\end{array}$ & $\begin{array}{c}0.51 \\
{[0.20,0.82]}\end{array}$ & $\begin{array}{c}0.46 \\
{[0.21,0.74]}\end{array}$ & $\begin{array}{c}0.50 \\
{[0.20,0.82]}\end{array}$ & $\begin{array}{c}0.44 \\
{[0.21,0.68]}\end{array}$ \\
\hline$M_{s, \zeta}$ & - & - & $\begin{array}{c}-1.19 \\
{[-2.28,-0.46]}\end{array}$ & $\begin{array}{c}-0.12 \\
{[-1.40,1.58]}\end{array}$ & $\begin{array}{c}-0.01 \\
{[-1.55,1.67]}\end{array}$ \\
\hline$M_{g, \zeta}$ & $\begin{array}{c}0.94 \\
{[-0.76,2.28]}\end{array}$ & $\begin{array}{c}0.61 \\
{[-0.97,1.91]}\end{array}$ & $\begin{array}{c}0.78 \\
{[-0.37,1.95]}\end{array}$ & $\begin{array}{c}0.10 \\
{[-1.46,1.67]}\end{array}$ & $\begin{array}{c}0.00 \\
{[-1.54,1.68]}\end{array}$ \\
\hline$M_{r, \zeta}$ & $\begin{array}{c}0.18 \\
{[-1.29,1.68]}\end{array}$ & $\begin{array}{c}0.09 \\
{[-1.60,1.65]}\end{array}$ & $\begin{array}{c}0.39 \\
{[-1.16,2.06]}\end{array}$ & $\begin{array}{c}0.10 \\
{[-1.50,1.70]}\end{array}$ & $\begin{array}{c}0.01 \\
{[-1.57,1.62]}\end{array}$ \\
\hline$M_{d, \zeta}$ & $\begin{array}{c}0.07 \\
{[-1.69,1.75]}\end{array}$ & $\begin{array}{c}0.16 \\
{[-1.60,1.95]}\end{array}$ & $\begin{array}{c}-0.16 \\
{[-1.89,1.46]}\end{array}$ & $\begin{array}{c}0.02 \\
{[-1.36,1.92]}\end{array}$ & $\begin{array}{c}0.08 \\
{[-1.50,1.74]}\end{array}$ \\
\hline$M_{\nu, \zeta}$ & - & - & $\begin{array}{c}-0.23 \\
{[-1.82,1.52]}\end{array}$ & $\begin{array}{c}-0.02 \\
{[-1.62,1.56]}\end{array}$ & $\begin{array}{c}0.01 \\
{[-1.60,1.64]}\end{array}$ \\
\hline$\lambda$ & - & - & - & - & $\begin{array}{c}1.05 \\
{[0.66,1.43]}\end{array}$ \\
\hline$\sigma_{e_{1}}$ & - & - & - & - & $\begin{array}{c}0.36 \\
{[0.19,0.51]}\end{array}$ \\
\hline$\sigma_{e_{2}}$ & - & - & - & - & $\begin{array}{c}0.47 \\
{[0.33,0.63]} \\
\end{array}$ \\
\hline
\end{tabular}



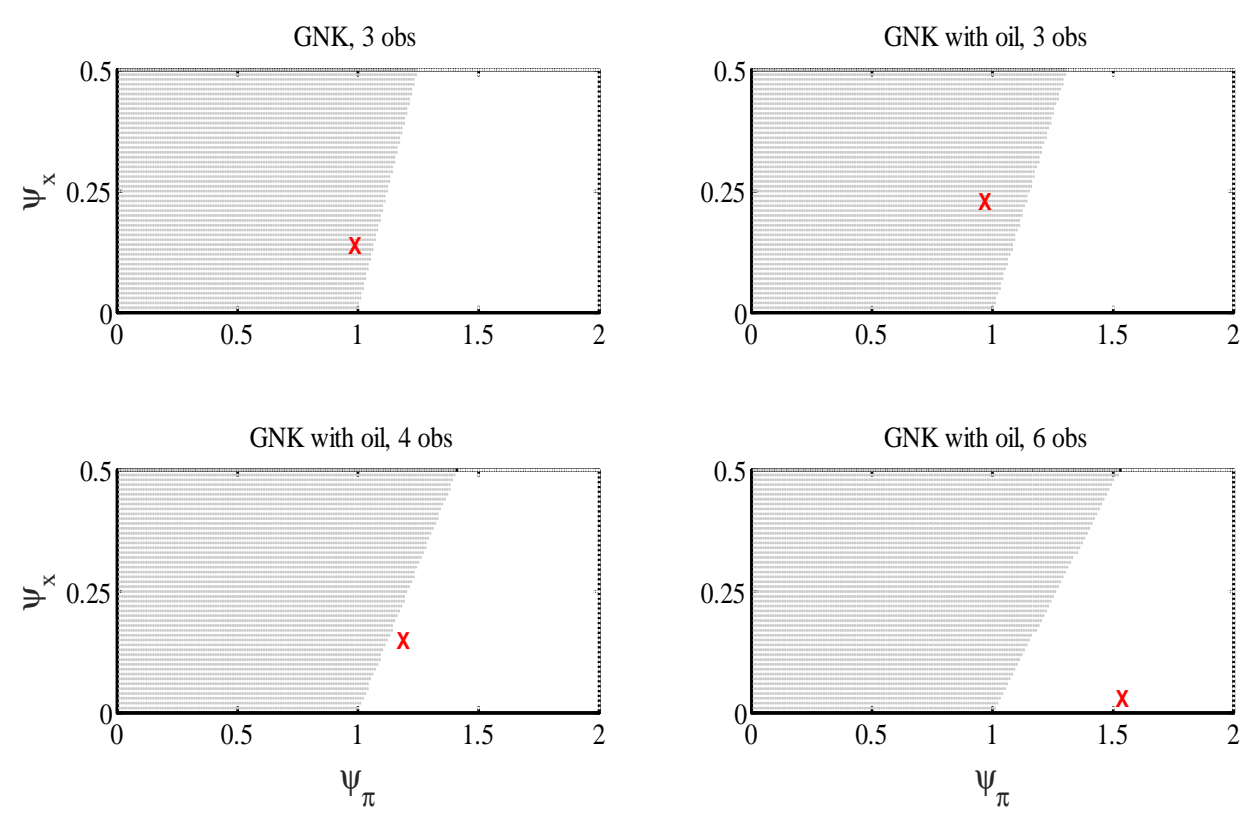

Figure 3: Indeterminacy regions in the $\psi_{\pi}-\psi_{x}$ space.

South East panel. In all cases, the parameters (other than $\psi_{\pi}$ and $\psi_{x}$ ) are set at their posterior mean and crosses locate the posterior mean of the two policy parameters. Reminiscent of Ascari and Ropele (2009) and Coibion and Gorodnichenko (2011), the areas displayed in Figure 3 imply that responding to the output gap is destabilizing. The North West panel reports results that are in line with the substantial uncertainty found in the literature about whether or not the Taylor principle was satisfied in the pre-Volcker era (Clarida et al. 2000; Orphanides 2004; Lubik and Schorfheide 2004; Coibion and Gorodnichenko 2011; Hirose et al. 2017). Instead, in the South East panel which involves estimation with all six observables, the combination of a clearly active $\psi_{\pi}$ and a virtually zero $\psi_{x}$ puts the economy unambiguously into the determinacy region. ${ }^{21}$

To summarize so far, through the lens of our model, we do not find support for the thesis that the Federal Reserve failed to respond aggressively to inflation. Once wage data is included as an observable, a significant degree of real wage rigidity arises for the 1970s and this rigidity breaks down the divine coincidence. Together

\footnotetext{
${ }^{21}$ The non-reaction to the output gap is compensated by a marked response to output growth which is also stabilizing (see Coibion and Gorodnichenko, 2011, Orphanides and Williams 2006, and Walsh, 2003).
} 
with commodity price shocks, this opens the door for a trade-off between stabilizing inflation and the output gap for which we can account for. This trade-off considerably affects the estimates of the systematic component of monetary policy. As a result, indeterminacy of the system disappears as an explanation of the Great Inflation.

\subsection{A closer look at parameter estimates and the Great Mod- eration}

Table 4 details the parameter estimates. We find that the estimated response to inflation in the Taylor rule is passive for the GNK model estimated using three observables. This result is in line with the previous literature. When we use both headline and core inflation measures in the estimation we are able to identify the commodity price shocks and the response to inflation turns active. Yet, that is not enough to completely rule out indeterminacy as the Taylor principle is not sufficient to guarantee a determinate equilibrium in a model with trend inflation. However, once we add both wage data to our estimation, the degree of real wage rigidity becomes significantly higher: the point estimate sits at around 0.9. Such a high degree of real wage rigidity worsens the trade-off faced by the central bank in the wake of commodity price shocks and our intuition is that the Taylor rule parameters are influenced by this policy trade-off. Our estimation reflects this as the response to inflation $\psi_{\pi}$ turns strongly active at more than 1.5. At the same time, the Federal Reserve's response to the real economy changed: the policy parameter to the output gap $\psi_{x}$ drops to only 0.03 while its response to output growth $\psi_{g}$ becomes stronger (0.33). Combined, such changes to the Taylor Rule parameters push the posterior distribution toward the determinacy region of the parameter space.

This result can be understood as follows. Real wage rigidity dampens the effect of trend inflation on indeterminacy as documented earlier. Given the estimated levels of rigidity and trend inflation, the minimum response to inflation required to ensure determinacy is much lower than in a model with flexible real wages (recall Figure 1). As such, a strong response to inflation is almost sufficient to guarantee determinacy. Then, the estimated weak response to the output gap pushes the economy explicitly 
into the determinacy region. ${ }^{22}$

Let us next compare the pre-Volcker and the Great Moderation periods (you can follow this in the last two columns of Table 1). The key finding is that the policy responses to inflation and output growth almost double while trend inflation falls, which aligns with Coibion and Gorodnichenko (2011). The policy response to the output gap $\psi_{x}$ remains relatively weak. Also, the Federal Reserve moves its focus away from responding to headline inflation toward core inflation during the Great Moderation. This echoes Mehra and Sawhney (2010). ${ }^{23}$ Lastly, real wage rigidity declines over time, however, unlike Blanchard and Riggi (2013), the point estimate still implies a considerable degree of rigidity. This difference of results is most likely reflected in the different estimation strategies: Blanchard and Riggi (2013) adopt a limited information approach that matches impulse responses to an oil price shock in their DSGE model and in a structural VAR while we use full-information Bayesian estimation with multiple shocks. The volatilities of both commodity price shocks and labor supply shocks increase across the two periods (as seen in Table 1). As in Bjørnland et al. (2018), this rise in the volatility of commodity price shocks could simply reflect more episodes of high oil price volatility in the post-1984 period. Innovations to the variance of monetary policy shocks and discount factor shocks decline quite considerably while the size of the technology shock remain fairly stable.

What is the estimated model's ability to capture the Great Moderation, in particular the marked decline in macroeconomic volatility since the mid-1980s? Table 5 summarizes the model's implications for the volatility of inflation (both headline and core) and output growth - evaluated at its posterior mean - along with U.S. data. The estimated model replicates the observed volatility drops. ${ }^{24}$ Despite the fact that our model is relatively small compared to models of Smets and Wouters (2007) or Justiniano and Primiceri (2008), the replication is assuring in terms of the empirical plausibility of our estimation results.

\footnotetext{
${ }^{22}$ Hirose et al. (2017) report a smaller estimate for $\psi_{\pi}$ and a larger estimate for $\psi_{x}$ implying indeterminacy, which resonates our estimates in cases where commodity price shocks and wage rigidity are either absent or not identified properly.

${ }^{23}$ For a related analysis see Doko Tchatoka et al. (2017).

${ }^{24}$ Although it overestimates the standard deviation, such mismatch is also present in medium-scale models as well (see Smets and Wouters, 2007).
} 
Table 5: The Great Moderation

\begin{tabular}{ccccccc}
\hline \hline & \multicolumn{2}{c}{$1966:$ I-1979:II } & \multicolumn{2}{c}{ 1984:I-2008:II } & \multicolumn{2}{c}{ Percent Change } \\
\cline { 2 - 7 } & Data & Model & Data & Model & Data & Model \\
\cline { 2 - 7 } Headline Inflation & 0.68 & 1.04 & 0.38 & 0.45 & $-44 \%$ & $-56 \%$ \\
Core Inflation & 0.60 & 0.88 & 0.28 & 0.26 & $-53 \%$ & $-70 \%$ \\
Output Growth & 1.01 & 1.14 & 0.53 & 0.63 & $-48 \%$ & $-45 \%$ \\
& & & & & & \\
\hline \hline
\end{tabular}

\subsection{Identification issues}

We close this section by addressing two aspects pertaining to the estimation. First, Figure 4 underlines how identification of oil-price shocks is achieved when using both headline and core inflation data in the estimation. It displays the smoothed estimates of the real commodity prices, shown here as the quarterly growth rate in deviations from the steady state (i.e. commodity price inflation). When the estimation employs only three observables. i.e. only one series for inflation, the estimated commodity price shows no spike around 1973-74 and 1979. That is, commodity price shocks are not identified. However, once the estimation utilizes both inflation data (i.e. the case of four observables), commodity price shocks become evident as spikes in both periods. The smoothed estimates are exactly the same for estimations that use wage data - they virtually overlap in the graph. This result indicates that the estimation requires headline and core inflation only to exactly pin down the commodity price shocks irrespective of the other observables used. In fact, that is exactly what one expects from equation (1) as it relates headline, core and commodity price inflation in the model. Yet, while the smoothed sequence predicts big shocks being present in early 1973, oil prices only began to take off at the beginning of 1974 . This is well explained by the increases in industrial commodity prices that preceded the oil price shocks (see Barsky and Kilian, 2001, and Bernanke et al., 1997) and is linked to our identification using core and headline inflation. Nonetheless, we also directly use oil price data as an observable and show that our results carry over.

Second, as the output gap takes on a central role in the model's interpretation of the economy, it is important to know if the estimated series of the output gap 


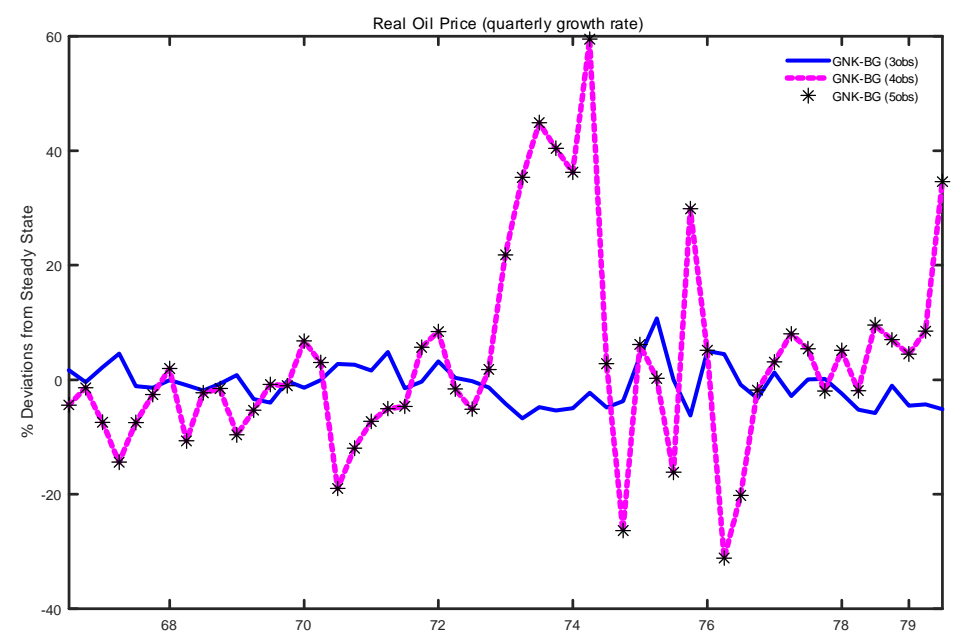

Figure 4: Identification of commodity price shocks

resembles empirical counterparts. Given that the estimation takes place in a system, it is a priori not necessary that the estimated series is close to an empirical proxy that is constructed using orthogonal information. Figure 5 shows that for all estimations that do not include wage data, the estimated series of the output gap is basically a flat line that has no resemblance to the Congressional Budget Office (CBO) based series. Phrased alternatively, while the use of two inflation series identify commodity price shocks, it falls short of doing the same regarding the output gap. Yet, once information on wages is included and the propagation dynamics set, the smoothed series of the output gap is highly correlated with the CBO data and, returning to Table 2, indeterminacy can then be ruled out for the Seventies.

\section{The comovement between inflation and the out- put gap}

Next, we explore how important real wage rigidity is in generating a negative relationship between inflation and economic activity. Figure 6 plots impulse response functions for headline inflation, core inflation, the output gap and price dispersion to a ten percent commodity price shock. To better sift out the role of slow wage 


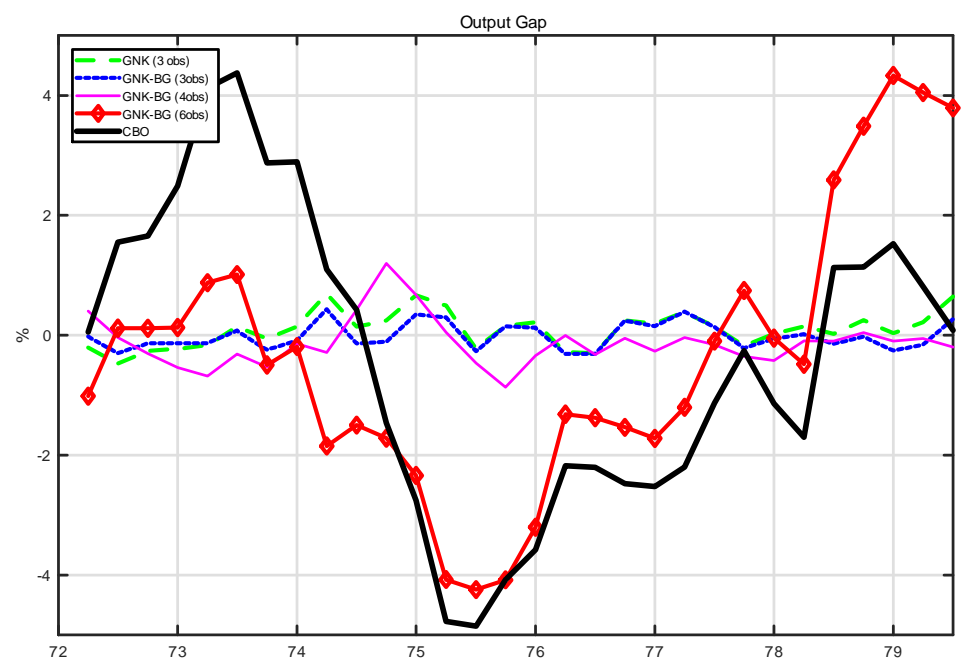

Figure 5: Output gaps vis-à-vis CBO.

adjustments, each plot considers three calibrations of the rigidity parameter $\gamma{ }^{25}$

In the presence of complete real wage flexibility, $\gamma=0$, headline inflation increases (mechanically with oil prices) while core inflation and price dispersion decrease and the output gap hardly moves at all. With flexible wages, an increase in the real price of oil reduces the real wage and consequently lowers marginal costs. As a result, both desired prices and price dispersion fall. On the other hand, for higher levels of real wage stickiness (e.g. $\gamma=0.9$ in Figure 6), output and inflation negatively comove and policy-makers face a trade-off between output gap and inflation (both headline and core) stabilization. With real wages being rigid, an increase in the real price of oil results in an increase in the firms' marginal costs as well as desired prices and core inflation. Also, price dispersion increases which leads to further endogenous rise in inflation. Therefore, higher real wage rigidity generates a significant trade-off for the central bank following a commodity price shock. A stable output gap is thus inconsistent with either stable headline and/or core inflation.

\footnotetext{
${ }^{25}$ The structural parameters as well as the policy parameters are calibrated to their estimated posterior mean values for the pre-1979 period.
} 

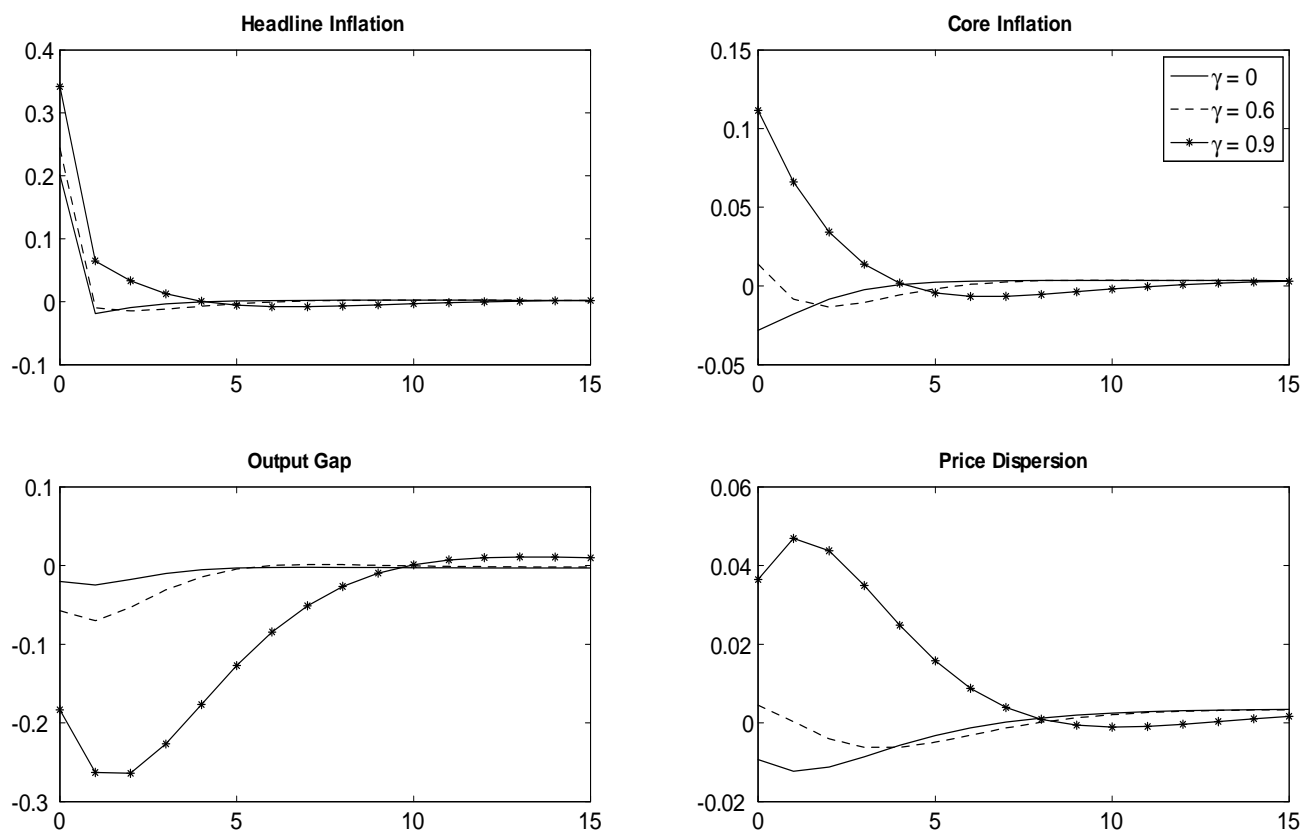

Figure 6: Model-based impulse response functions to a positive commodity price shock

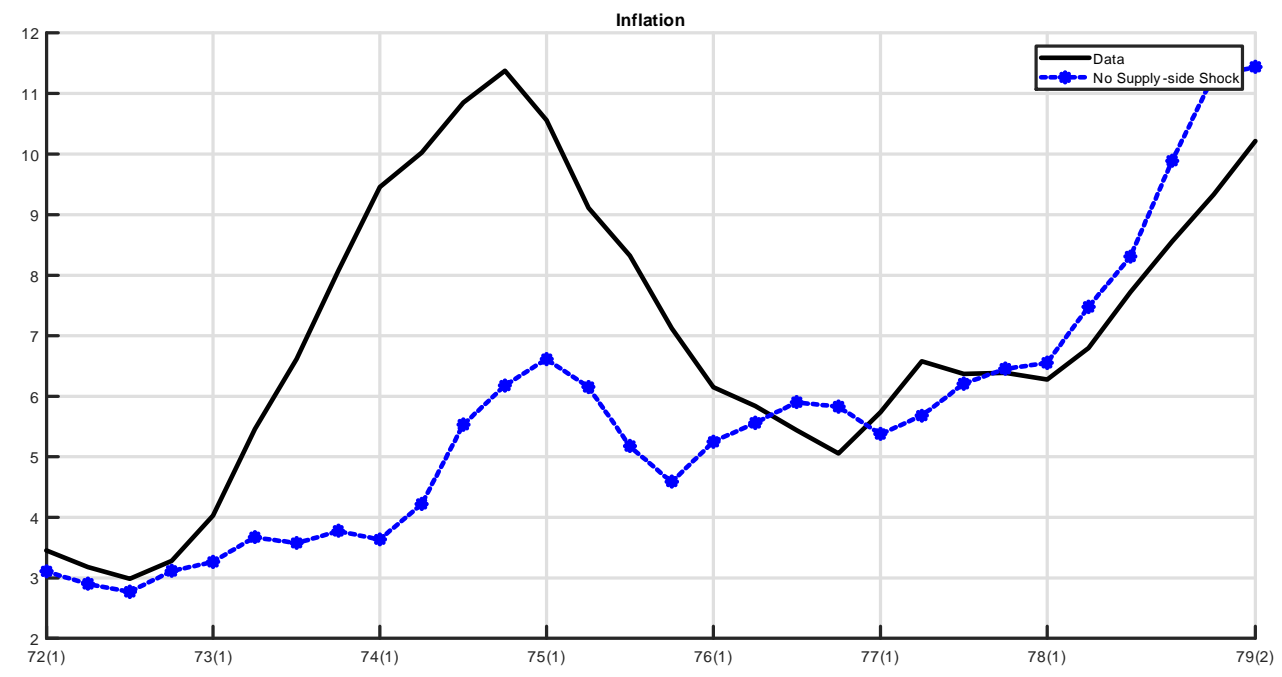

Figure 7: Counterfactual path of inflation (y-o-y) in absence of aggregate supply shocks. 


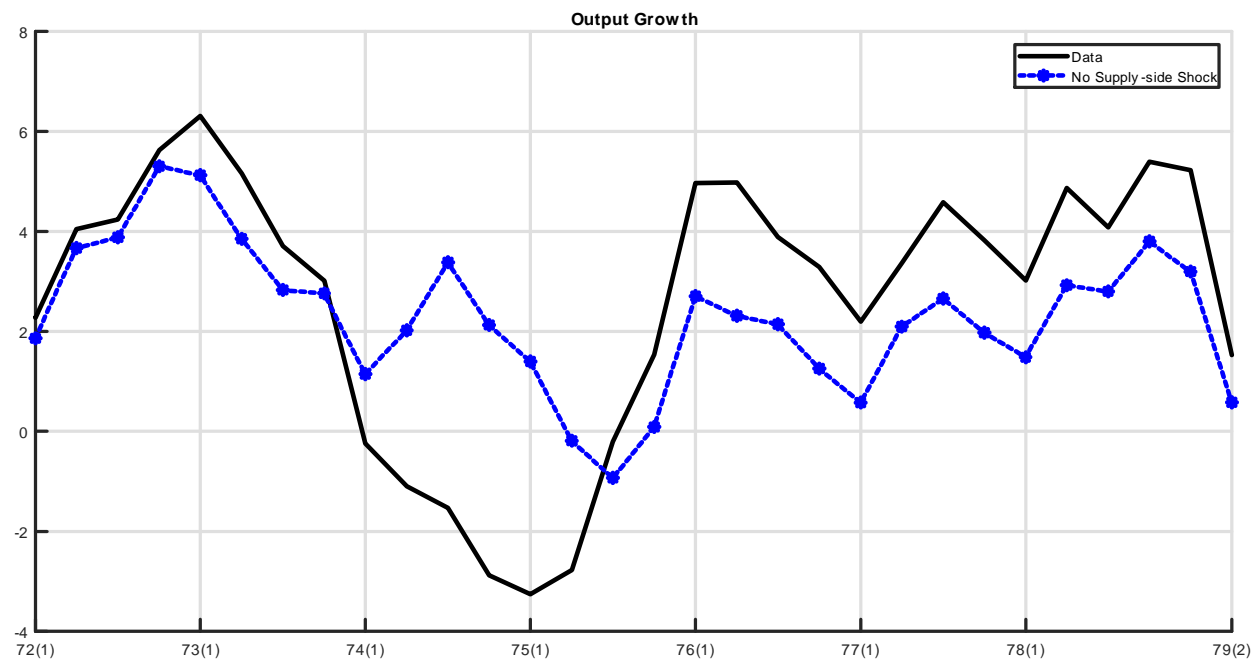

Figure 8: Counterfactual path of output growth (y-o-y) in the absence of aggregate supply shocks.

\section{What caused the stagflation?}

The above results suggest that monetary policy was active in the Seventies and, through the lens of our trend inflation model, indeterminacy was not the likely factor behind the high inflation rates. Rather, our estimation points to supply shocks similar to Gordon (1977) and Blinder (1982) to have caused the Great Inflation. To demonstrate this, we next undertake counterfactuals where we shut down the smoothed series of estimated supply shocks. This allows to extract the shocks' relative effects on the observed paths of inflation and output growth and in particular on their stagflationary pattern in the mid-1970s. Figures 7 and 8 plot the counterfactual paths along with actual data. Once the supply shocks are gone, the rise of inflation from 1973 to 1975 disappears to a large extent. Furthermore, the drop in output is significantly smaller. In sum, without supply shocks, the first stagflationary episode would not have taken place. 

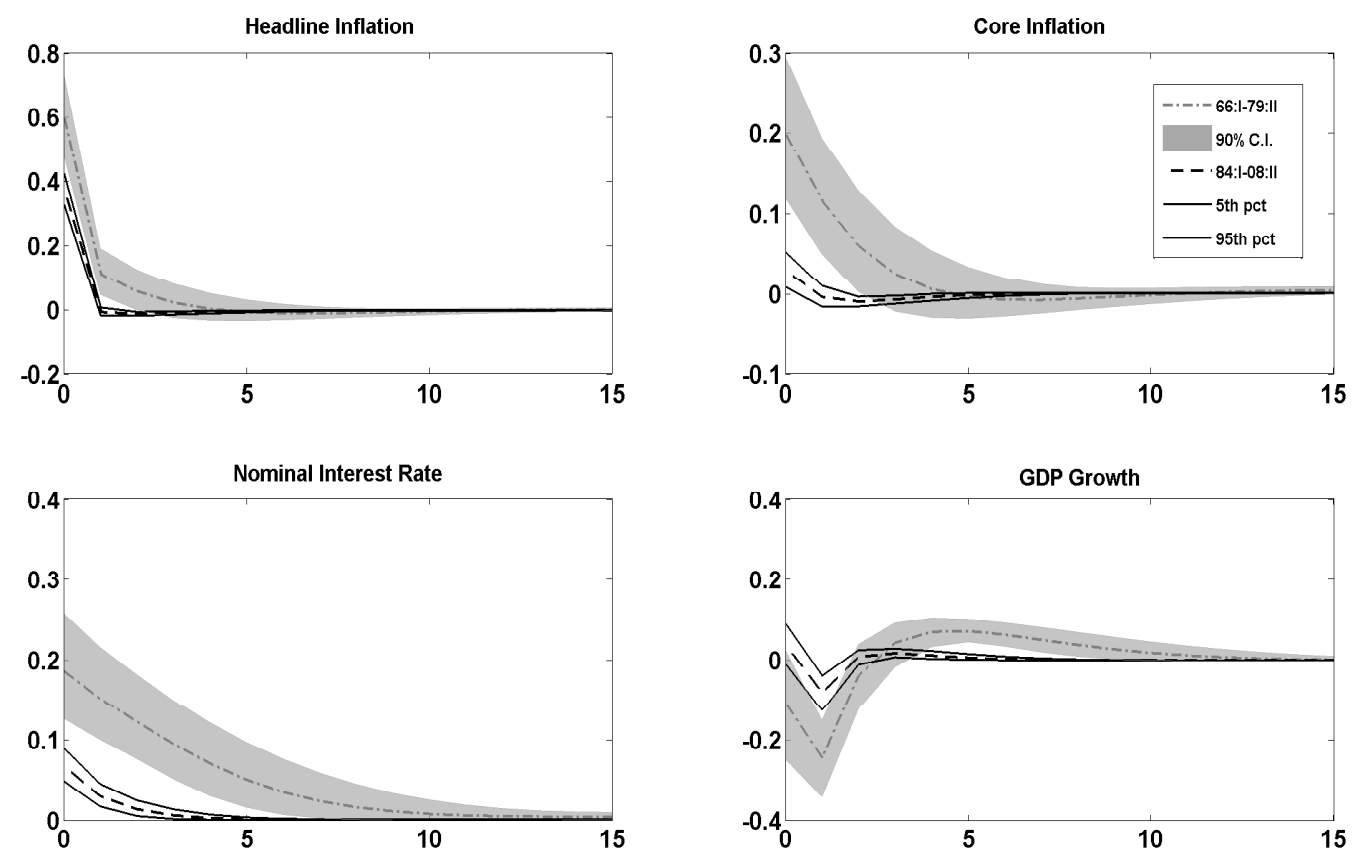

Figure 9: Bayesian impulse response functions to a positive commodity price shock

\section{Changes in the propagation of commodity price shocks}

This section studies how the propagation of commodity price shocks has changed over time. We begin by depicting the estimated mean impulse responses of headline inflation, core inflation, nominal interest rate and output growth for both sample periods along with the 90 percent probability intervals. Figure 9 shows that the effects of commodity price shocks have changed significantly over time: we find much smaller effects on core inflation, real activity and interest rate in the second subsample, despite the fact that the shocks are slightly larger in size. Only the impact response of headline inflation is similar, albeit with a smaller persistence. This is intuitive since, as argued above, part of the rise in oil prices is reflected automatically in the oil component of headline inflation. Overall, these findings are reassuring as they match the empirical VAR evidence put forth by Blanchard and Galí (2010), Blanchard and Riggi (2013) and in particular Kilian (2008, 2009) as well as Barsky and Kilian (2001, 2004) and others. 

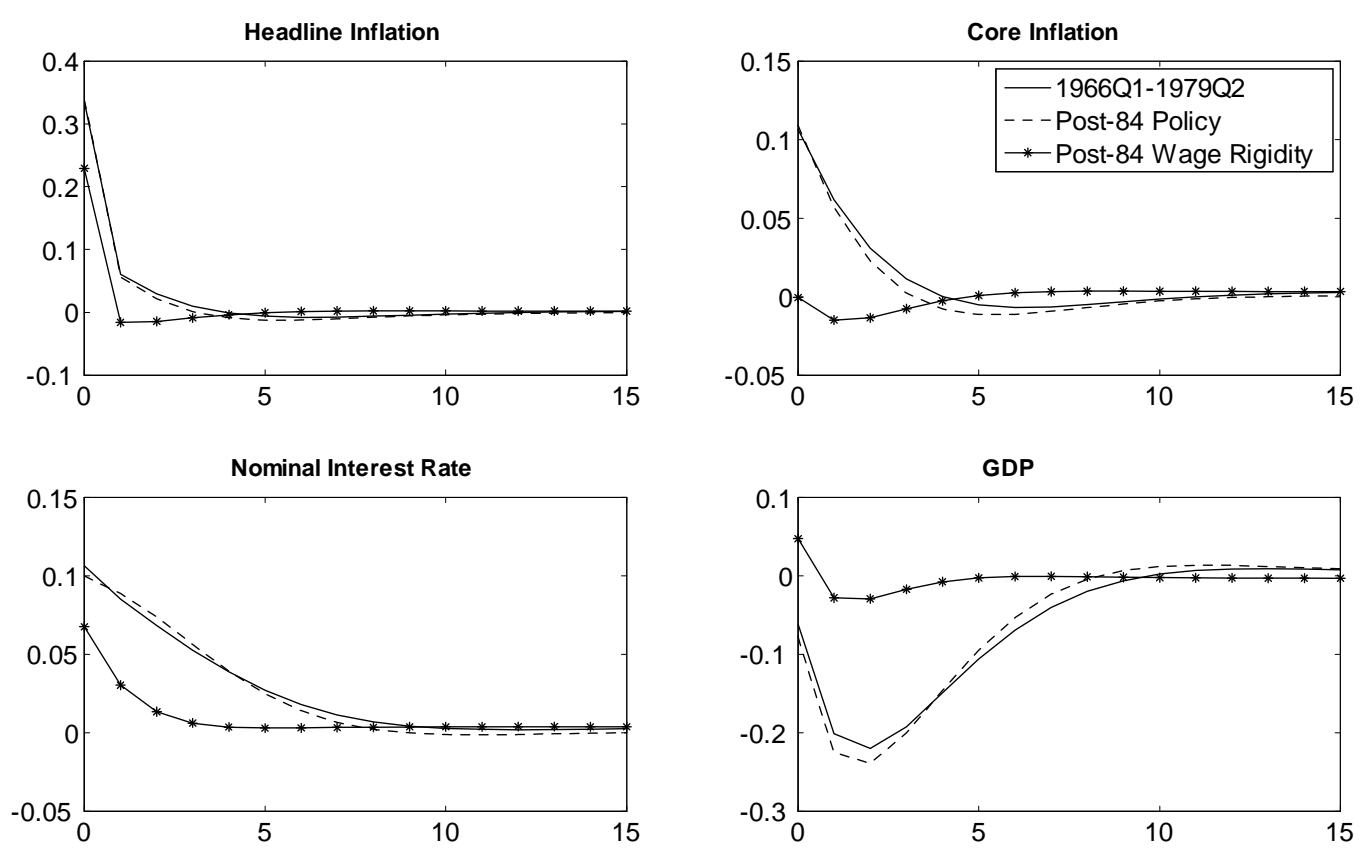

Figure 10: Counterfactual impulse response functions to a commodity price shock

Next, a counterfactual experiment will disentangle the driving force behind these changes over time. We divide the experiment into two categories. First, we combine the posterior mean estimates pertaining to the Taylor rule, i.e. $\psi_{\pi}, \psi_{x}, \psi_{\Delta y}, \rho_{R}, \pi^{*}$, and $\tau$, of the post-1984 sub-sample with the remaining parameter estimates of the pre1979 period which is called 'post-84 policy'. This exercise is designed to capture the role of monetary policy in reducing the effect of a given change in commodity prices. In the second category, we combine the posterior mean estimates of the pre-1979 period (including the policy parameters) with the estimated (lower) real wage rigidity from the post-1984 period, labelled 'post-84 wage rigidity'. This scenario is designed to capture the role of the decline in real wage rigidity as a possible explanation. Figure 10 depicts the impulse responses to a ten percent commodity price shock under the two alternative scenarios, while calibrating the remaining parameters at the posterior mean estimates of the pre-1979 period. Looking at the figure, we can see that the decline in the effects of commodity price shocks are mainly explained by a reduction in real wage rigidity. As argued earlier, real wage rigidity generates a trade-off between inflation and output gap stabilization. A shift toward more flexible wages implies 
a reduction in this trade-off, thereby explaining the smaller effects of the shocks in the more recent period. Our finding corroborates one of the hypotheses put forth by Blanchard and Galí (2010) and is also in line with the empirical evidence documented in Blanchard and Riggi (2013).

\section{Robustness of determinacy}

We now conduct a battery of sensitivity checks with respect to our main result. Directions involve (i) an alternative Taylor rule, (ii) alternative formulation of the boundary between the determinacy and indeterminacy region, (iii) flexible-price output gap, (iv) indexation to past inflation, and (v) using oil price data as an observable. For all these cases, the estimation is conducted while including both wage series. Table 6 summarizes the log-data densities and the posterior probabilities for all checks, while the parameter estimates are delegated to Tables A1 and A2 in the Appendix.

\subsection{Alternative Taylor rule}

Justiniano, Primiceri and Tambalotti (2013) propose an alternative formulation of the monetary policy rule that features a systematic response to deviations of annual inflation from a positive trend and to deviations of observed annual GDP growth from its steady state level. ${ }^{26}$ Thus, we re-estimate the model by replacing the policy rule (5) with the following formulation:

$\frac{R_{t}}{\bar{R}}=\left(\frac{R_{t-1}}{\bar{R}}\right)^{\rho_{R}}\left(\left[\left(\frac{\left(\prod_{s=0}^{3} \pi_{c, t-s}\right)^{\frac{1}{4}}}{\bar{\pi}}\right)^{\tau}\left(\frac{\left(\prod_{s=0}^{3} \pi_{q, t-s}\right)^{\frac{1}{4}}}{\bar{\pi}}\right)^{1-\tau}\right]^{\psi_{\pi}}\left[\frac{Y_{t}}{Y_{t}^{*}}\right]^{\psi_{x}}\left[\frac{\left(\frac{Y_{t}}{Y_{t-1}}\right)^{\frac{1}{4}}}{\bar{g}}\right]^{\psi_{g}}\right]^{1-\rho_{R}} e^{\varepsilon_{R, t}}$.

We find a stronger response to output growth in both periods which is somewhat similar in magnitude to what Justiniano, Primiceri and Tambalotti (2013) report. Other than this, the determinacy result carries over (see Table 6, first row).

\footnotetext{
${ }^{26}$ Strictly speaking, the feedback rule specified by Justiniano, Primiceri and Tambalotti (2013) features a time-varying inflation target and does not include an output gap measure.
} 
Table 6: Determinacy versus Indeterminacy (Robustness)

\begin{tabular}{|c|c|c|c|}
\hline \multirow{6}{*}{ 1966:I-1979:II } & & Log-data density & Probability of det. \\
\hline & JPT Taylor rule & -287.06 & 0.9 \\
\hline & Boundary & -280.59 & 0.8 \\
\hline & Flex-price output gap & -276.72 & 0.9 \\
\hline & Indexation & -278.42 & 1 \\
\hline & Core CPI \& Oil & -504.87 & 0.8 \\
\hline \multirow[t]{5}{*}{ 1984:I-2008:II } & JPT Taylor rule & -290.13 & 1 \\
\hline & Boundary & -277.74 & 1 \\
\hline & Flex-price output gap & -280.45 & 1 \\
\hline & Indexation & -286.62 & 1 \\
\hline & Core CPI \& Oil & -625.10 & 1 \\
\hline
\end{tabular}




\subsection{Crossing the boundary}

The presence of positive trend inflation enriches the dynamics of the model and the usual Taylor principle, i.e. $\psi_{\pi}>1$, is no longer a sufficient condition for local determinacy. The higher-order dynamics make it infeasible to analytically derive the indeterminacy conditions. To continue solving the model via Lubik and Schorfheide's (2004) method, where $M^{*}(\theta)$ is selected such that the responses of the endogenous variables to the fundamental shocks are continuous at the boundary, one needs to resort to numerical methods. So far, we have perturbed $\psi_{\pi}$ to numerically trace the boundary. However, in the presence of trend inflation, this boundary becomes a com-

plicated function of $\psi_{\pi}$ along with the other Taylor Rule coefficients as well as the other structural parameters. As such, the indeterminacy test might become susceptible to how we trace the boundary. Hence, as a robustness check, we alternatively drag both the response to inflation $\psi_{\pi}$ as well as the response to the output gap $\psi_{x}$. Nothing changes as we again find that data favors determinacy and the response to inflation is active, even during the Great Inflation.

\subsection{Flexible-price output gap}

In the analysis thus far, we have focused on the welfare-relevant output gap, defined as the deviation of actual output from its efficient level. Nevertheless, we have also estimated the model with the flexible-price output gap in the Taylor rule, defined as the deviation of actual output from its natural level prevailing under flexible prices. As pointed by Blanchard and Riggi (2013), the natural level of output fluctuates more with respect to oil price changes in a model with real wage rigidity. As a result, the flexible-price output gap turns out to be more volatile than the welfarerelevant output gap. We then find that the estimated response to the output gap turns out to be somewhat higher in the pre-1979 period. Yet, the findings that the pre-Volcker period is characterized by strongly active response to inflation and determinacy remain unchanged. 


\subsection{Indexation}

So far, the model has been estimated assuming the absence of rule-of-thumb pricesetting in light of Cogley and Sbordone's (2008) reported lack of intrinsic inertia in the GNK Phillips Curve. We now estimate the model while allowing for indexation. We follow Ascari et al. (2011) and estimate the degree of indexation to past inflation, which is also in line with Benati (2009). While finding some support for a moderate degree of indexation, the fourth row of Table 6 shows that the pre-Volcker period is still best characterized by determinacy.

\subsection{Oil as an observable}

Lastly, we investigate the sensitivity of our results to directly using real oil price data as an observable. Until now we have simultaneously employed both headline and core inflation measures as observables. This choice identifies the cost-push shocks as commodity price shocks in general (which includes the price of food and other commodities as well). For instance, the two inflationary episodes in the 1970s also featured sizeable food-price hikes as documented by Blinder and Rudd (2012). Since food has a much larger weight in the price indexes than energy, ignoring them might constitute a key omission. Nonetheless, we also check the robustness of our results to directly using percentage change of the real price of oil as an observable to identify the episodes of oil price shocks in isolation. As such, we use the West Texas Intermediate oil price data. ${ }^{27}$ We deflate the nominal oil price by the core consumer price index to align it with the concept of real oil price in the model. The resulting series is then demeaned by its sub-sample mean prior to the estimation. We continue to use data on quarterly growth rate of GDP per capita, core CPI, the two (real) wage inflation series and the Federal Funds rate. Again, our results remain robust as you can see in the fifth row of Table 6 .

\footnotetext{
${ }^{27}$ Nakov and Pescatori (2010) use this same oil price series and find that oil played an important role in the Great Moderation.
} 


\section{Conclusion}

Was the Great Inflation really caused by endogenous decisions, i.e. destabilizing monetary policies? This question has engaged many researchers since Clarida et al. (2000) who estimate the monetary policy rule in isolation, find a passive response to inflation which suggests that U.S. monetary policy before 1979 was consistent with equilibrium indeterminacy. Lubik and Schorfheide (2004) offer a parallel argument while treating indeterminacy as a property of a system (i.e. the New Keynesian model): loose monetary policy led to mercurial inflation. A similar conclusion appears in models with trend inflation. Coibion and Gorodnichenko (2011) using single-equation estimations and Hirose et al. (2017) employing general equilibrium estimations both suggest that the Great Inflation can be best understood as the result of equilibrium indeterminacy.

The current paper advances an alternative hypothesis that blames exogenous factors. This exercise is done in an estimated GNK economy which simultaneously considers trend inflation, real wage sluggishness and supply shocks in the form of oil. In such an environment, sticky wages and inefficient supply shocks generate a strong negative correlation between inflation and the output gap, thereby confronting the monetary authority with a difficult trade-off. Such an environment necessitates a full system estimation that takes into account this trade off such that the parameter estimates of the Taylor rule allow for the endogeneity of its targeted variables. Our analysis provides evidence for sluggish real wages and makes the case that the U.S. monetary policy before 1979 was inconsistent with equilibrium indeterminacy. In particular, we find that the Federal Reserve responded aggressively to inflation while its response to the output gap was almost negligible. Taken together, these responses imply that monetary policy had no destabilizing effect even in the Seventies. Phrased alternatively, we do not find empirical evidence for indeterminacy in the U.S. economy and this brings about an important implication for interpreting the Great Inflation: to a large extent it was driven by unfavorable supply shocks. We also estimate the model over the Great Moderation period and are able to account for the decline in macroeconomic volatility. We further document that oil price shocks are no longer as inflationary and a decline in real wage rigidity helps explain the remarkable resilience of the U.S. economy to sustained oil price fluctuations in the 2000s. 


\section{References}

[1] Abraham, K. and J. Haltiwanger (1995): "Real Wages and the Business Cycle", Journal of Economic Literature 33, 1215-1264.

[2] Alves, S. (2014): "Lack of Divine Coincidence in New Keynesian Models", Journal of Monetary Economics 67, 33-46.

[3] Arias, E., G. Ascari, N. Branzoli and E. Castelnuovo (2019): "Positive Trend Inflation and Determinacy in a Medium-Sized New-Keynesian Model", International Journal of Central Banking (in press).

[4] Araújo, E. (2009): "Real Wage Rigidity and the Taylor Principle", Economics Letters $104,46-48$.

[5] Ascari, G., P. Bonomolo and H. Lopes (2019): "Walk on the Wild Side: Temporarily Unstable Paths and Multiplicative Sunspots", American Economic Review (in press).

[6] Ascari, G., E. Castelnuovo and L. Rossi (2011): "Calvo vs. Rotemberg in a Trend Inflation World: An Empirical Investigation", Journal of Economic Dynamics and Control 35, 1852-1867.

[7] Ascari, G. and T. Ropele (2009): "Trend Inflation, Taylor Principle, and Indeterminacy", Journal of Money, Credit and Banking 41, 1557-1584.

[8] Ascari, G. and A. Sbordone (2014): "The Macroeconomics of Trend Inflation", Journal of Economic Literature 52, 679-739.

[9] Bachmeier, L. and B. Keen (2017): "Modeling the Asymmetric Effects of Oil Price Shocks", mimeo.

[10] Barsky, R. and L. Kilian (2001): "Do We Really Know That Oil Caused the Great Stagflation? A Monetary Alternative", NBER Macroeconomics Annual 16, 137-183.

[11] Barsky, R. and L. Kilian (2004): "Oil and the Macroeconomy since the 1970s", Journal of Economic Perspectives 18, 115-134. 
[12] Barsky, R., S. Basu and K. Lee (2015): "Whither News Shocks?", NBER Macroeconomics Annual 29, 225-264.

[13] Basu, S. and C. House (2016): "Allocative and Remitted Wages", in: J. Taylor and H. Uhlig (editors) Handbook of Macroeconomics 2, Elsevier, 297-354.

[14] Beaudry, P. and J. DiNardo (1991): "The Effect of Implicit Contracts on the Movement of Wages over the Business Cycle: Evidence from Micro Data," Journal of Political Economy 99, 665-688.

[15] Benati, L. (2009): "Are 'Intrinsic Inflation Persistence' Models Structural in the Sense of Lucas (1976)?", European Central Bank Working Paper No. 1038.

[16] Bernanke, B., M. Gertler and M. Watson (1997): "Systematic Monetary Policy and the Effects of Oil Price Shocks", Brookings Papers on Economic Activity 28, 91-157.

[17] Bianchi, F and G. Nicolò (2019): "A Generalized Approach to Indeterminacy in Linear Rational Expectations Models", mimeo.

[18] Bjørnland, H., V. Larsen and J. Maih (2018): "Oil and Macroeconomic (In)stability", American Economic Journal: Macroeconomics, 10, 128-151.

[19] Blanchard, O. and J. Galí (2007): "Real Wage Rigidities and the New Keynesian Model", Journal of Money, Credit and Banking 39, 35-65.

[20] Blanchard, O. and J. Galí (2010): "The Macroeconomic Effects of Oil Price Shocks: Why are the 2000s so different from the 1970s?", in: J. Galí and M. Gertler (editors) International Dimensions of Monetary Policy, University of Chicago Press, 373-428.

[21] Blanchard, O. and M. Riggi (2013): "Why are the 2000s so Different from the 1970s? A Structural Interpretation of Changes in the Macroeconomic Effects of Oil Prices", Journal of the European Economic Association 11, 1032-1052.

[22] Blinder, A. (1981): "Supply-shock Stagflation: Money, Expectations and Accommodation", in: J. Flanders and A. Razin (editors) Developments in an Inflationary World, Academic Press, 61-101. 
[23] Blinder, A. (1982): "The Anatomy of Double-Digit Inflation in the 1970s", in: R. Hall (editor) Inflation: Causes and Effects, University of Chicago Press, 261-282.

[24] Blinder, A. and J. Rudd (2012): "The Supply-Shock Explanation of the Great Stagflation Revisited", in: M. Bordo and A. Orphanides (editors) The Great Inflation: The Rebirth of Modern Central Banking, University of Chicago Press, 119-175.

[25] Bodenstein, M., C. Erceg and L. Guerrieri (2008): "Optimal Monetary Policy with Distinct Core and Headline Inflation Rates", Journal of Monetary Economics 55, S18S33.

[26] Boivin, J. and M. Giannoni (2006): "DSGE Models in a Data-rich Environment", NBER Working Paper No. 12772.

[27] Clarida, R., J. Galí and M. Gertler (2000): "Monetary Policy Rules and Macroeconomic Stability: Evidence and Some Theory", Quarterly Journal of Economics 115, 147-180.

[28] Cogley, T. and A. Sbordone (2008): "Trend Inflation, Indexation, and Inflation Persistence in the New Keynesian Phillips Curve", American Economic Review 98, 21012126 .

[29] Coibion, O. and Y. Gorodnichenko (2011): "Monetary Policy, Trend Inflation, and the Great Moderation: An Alternative Interpretation", American Economic Review 101, $341-370$.

[30] Devereux, P. (2001): "The Cyclicality of Real Wages within Employer-employee Matches", Industrial and Labor Relations Review 54, 835-850.

[31] Doko Tchatoka, F., N. Groshenny, Q. Haque and M. Weder (2017): "Monetary Policy and Indeterminacy after the 2001 Slump", Journal of Economic Dynamics and Control 82, 83-95.

[32] Farmer, R, V. Khramov and G. Nicolò (2015): "Solving and Estimating Indeterminate DSGE Models", Journal of Economic Dynamics and Control 54, 17-36.

[33] Gordon, R. (1977): "Can the Inflation of the 1970s be Explained?", Brookings Papers on Economic Activity 1, 253-277. 
[34] Hall, R. (2005): "Employment Fluctuations with Equilibrium Wage Stickiness", American Economic Review 95, 50-65.

[35] Herbst, E. and F. Schorfheide (2014): "Sequential Monte Carlo Sampling for DSGE Models", Journal of Applied Econometrics 29, 1073-1098.

[36] Herbst, E. and F. Schorfheide (2015): Bayesian Estimation of DSGE Models, Princeton University Press.

[37] Hirose, Y. (2014): "An Estimated DSGE Model with a Deflation Steady State", mimeo.

[38] Hirose, Y., Y. Kurozumi and W. Van Zandweghe (2017): "Monetary Policy and Macroeconomic Stability Revisited", mimeo.

[39] Jeanne, O. (1998): "Generating Real Persistent Effects of Monetary Shocks: How Much Nominal Rigidity Do We Really Need?", European Economic Review 42, 1009-1032.

[40] Justiniano, A. and G. Primiceri (2008): "The Time-varying Volatility of Macroeconomic Fluctuations", American Economic Review 98, 604-641.

[41] Justiniano, A., G. Primiceri and A. Tambalotti (2013): "Is There a Trade-off Between Inflation and Output Stabilization?", American Economic Journal: Macroeconomics $5,1-31$.

[42] Kilian, L. (2008): "Exogenous Oil Supply Shocks: How Big Are They and How Much Do They Matter for the U.S. Economy?", Review of Economics and Statistics 90, 216-240.

[43] Kilian, L. (2009): "Not All Oil Price Shocks Are Alike: Disentangling Demand and Supply Shocks in the Crude Oil Market", American Economic Review 99, 1053-1069.

[44] Liu, J. S., \& Chen, R. (1998). Sequential Monte Carlo Methods for Dynamic Systems, Journal of the American Statistical Association, 93(443), 1032-1044.

[45] Lubik, T. and C. Matthes (2016): "Indeterminacy and Learning: An Analysis of Monetary Policy in the Great Inflation", Journal of Monetary Economics 82, 85-106. 
[46] Lubik, T. and F. Schorfheide (2003): "Computing Sunspot Equilibria in Linear Rational Expectations Models", Journal of Economic Dynamics and Control 28, 273-285.

[47] Lubik, T. and F. Schorfheide (2004): "Testing for Indeterminacy: An Application to US Monetary Policy", American Economic Review 94, 190-217.

[48] Mehra, Y. and B. Sawhney (2010): "Inflation Measure, Taylor Rules, and the Greenspan-Bernanke Years", Federal Reserve Bank of Richmond Econonomic Quarterly $96,123-151$.

[49] Michaillat, P. (2012): "Do Matching Frictions Explain Unemployment? Not in Bad Times", American Economic Review 102, 1721-1750.

[50] Nakov, A. and A. Pescatori (2010) : "Oil and the Great Moderation", Economic Journal 120, 131-156.

[51] Natal, J. (2012): "Monetary Policy Response to Oil Price Shocks", Journal of Money, Credit and Banking 44, 53-101.

[52] Nicolò, G. (2018): "Monetary Policy, Expectations and Business Cycles in the U.S. Post-War Period", UCLA, mimeo.

[53] Orphanides, A. (2004): "Monetary Policy Rules, Macroeconomic Stability, and Inflation: A View from the Trenches," Journal of Money, Credit and Banking 36, 151-175.

[54] Orphanides, A. and J.C. Williams (2006): "Monetary policy with imperfect knowledge", Journal of the European Economic Association, 4(2-3), 366-375.

[55] Riggi, M. and F. Venditti (2014): "The Time Varying Effect of Oil Price Shocks on Euro Area Exports", Journal of Economic Dynamics and Control 59, 75-94.

[56] Smets, F. and R. Wouters (2007): "Shocks and Frictions in US Business Cycles: A Bayesian DSGE Approach", American Economic Review 97, 586-606.

[57] Uhlig, H. (2007): "Explaining Asset Prices with External Habits and Wage Rigidities in a DSGE Model", American Economic Review Papers and Proceedings 97, 239-243. 
[58] Walsh, C. (2003): "Speed limit policies: the output gap and optimal monetary policy", American Economic Review, 93(1), 265-278. 


\section{Appendix}

In this Appendix to "Do We Really Know that Monetary Policy was Destabilizing in the 1970s?", we provide the readers with a more detailed description of the data and model. We also report some of our estimation tables that we discuss (briefly) in the main paper but have decided to put into the Appendix to conserve space. We will begin by reporting the data and then set up the complete model. The Appendixes closes by reporting Tables A1 and A2.

\subsection{Data sources}

This part of the Appendix details the sources of the data used in the estimation. All data is quarterly and for the period 1966:I-2008:II.

1. Gross Domestic Product: U.S. Bureau of Economic Analysis, Real Gross Domestic Product [GDPC1], retrieved from FRED, Federal Reserve Bank of St. Louis https://fred.stlouisfed.org/series/GDPC1.

2. CPI: U.S. Bureau of Labor Statistics, Consumer Price Index for All Urban Consumers: All Items [CPIAUCSL], retrieved from FRED, Federal Reserve Bank of St. Louis https://fred.stlouisfed.org/series/CPIAUCSL.

3. Core CPI: U.S. Bureau of Labor Statistics, Consumer Price Index for All Urban Consumers: All Items Less Food and Energy [CPILFESL], retrieved from FRED, Federal Reserve Bank of St. Louis https://fred.stlouisfed.org/series/ CPILFESL.

4. Wage series 1: U.S. Bureau of Labor Statistics, Nonfarm Business Sector: Compensation Per Hour [PRS85006101], retrieved from FRED, Federal Reserve Bank of St. Louis

https://fred.stlouisfed.org/series/PRS85006101.

5. Wage series 2: U.S. Bureau of Labor Statistics, Average Hourly Earnings of Production and Nonsupervisory Employees: Total Private [AHETPI], retrieved from FRED, Federal Reserve Bank of St. Louis https://fred.stlouisfed.org/series/AHETPI. 
6. Federal Funds Rate: Board of Governors of the Federal Reserve System (US), Effective Federal Funds Rate [FEDFUNDS], retrieved from FRED, Federal Reserve Bank of St. Louis

https://fred.stlouisfed.org/series/FEDFUNDS.

7. Oil price: Dow Jones \& Company, Spot Oil Price: West Texas Intermediate (DISCONTINUED) [OILPRICE], retrieved from FRED, Federal Reserve Bank of St. Louis

https://fred.stlouisfed.org/series/OILPRICE.

\subsection{Model}

The artificial economy is a Generalized New Keynesian economy with a commodity product which we interpret as oil. The economy consists of monopolistically competitive wholesale firms that produce differentiated goods using labor and oil. These goods are bought by perfectly competitive firms who weld them together into the final good that can be consumed. People rent out their labor services on competitive markets. Firms and households are price takers on the market for oil. The economy boils down to a variant of the model in Blanchard and Gali (2010) when approximated around a zero inflation steady state.

\subsubsection{Households}

The representative agent's preferences depend on consumption, $C_{t}$, and hours worked, $N_{t}$, and they are represented by the expected utility function

$$
E_{0} \sum_{t=0}^{\infty} \beta^{t} d_{t} u\left(C_{t}, N_{t}\right) \quad 0<\beta<1
$$

which the agent acts to maximize. Here, $E_{t}$ represents the expectations operator. The term $d_{t}$ stands for a shock to the discount factor $\beta$ which follows the stationary autoregressive process

$$
\ln d_{t}=\rho_{d} \ln d_{t-1}+\epsilon_{d, t}
$$

where $\epsilon_{d, t}$ is a zero-mean, serially uncorrelated innovation that is normally distributed with standard deviation $\sigma_{d}$. The period utility is additively separable in consumption 
and hours worked and it takes on the functional form

$$
u\left(C_{t}, N_{t}\right)=\ln \left(C_{t}-h \widetilde{C}_{t-1}\right)-\nu_{t} \frac{N_{t}^{1+\varphi}}{1+\varphi} \quad \varphi \geq 0 .
$$

Logarithmic utility is the only additive-separable form consistent with balanced growth. The term $\varphi$ is the inverse of the Frisch labor supply elasticity, $h \in[0,1]$ stands for the degree of external habit persistence in consumption, and $\nu_{t}$ denotes a shock to the disutility of labor which follows

$$
\ln \nu_{t}=\rho_{\nu} \ln \nu_{t-1}+\epsilon_{\nu, t}
$$

where $\epsilon_{\nu, t}$ is $N\left(0, \sigma_{\nu}^{2}\right)$. The overall consumption basket, $C_{t}$, is a Cobb-Douglas bundle of output of domestically produced goods, $C_{q, t}$, and imported oil, $C_{m, t}$. In particular, we assume

$$
C_{t}=\Theta_{\chi} C_{m, t}^{\chi} C_{q, t}^{1-\chi} \quad 0<\chi<1
$$

where $\Theta_{\chi} \equiv \chi^{-\chi}(1-\chi)^{-(1-\chi)}$. The parameter $\chi$ equals the share of energy in total consumption. The agent sells labor services to the wholesale firms at the nominal wage $W_{t}$ and has access to a market for one-period riskless bonds, $B_{t}$, at the interest rate $R_{t}$. Any generated profits, $\Pi_{t}$, flow back and the period budget is constrained by

$$
W_{t} N_{t}+B_{t-1}+\Pi_{t} \geq P_{q, t} C_{q, t}+P_{m, t} C_{m, t}+\frac{B_{t}}{R_{t}}
$$

where $P_{q, t}$ denotes the domestic output price index. The Euler equation is given by

$$
\frac{d_{t}}{P_{c, t}\left(C_{t}-h C_{t-1}\right)}=\beta E_{t} \frac{R_{t} d_{t+1}}{P_{c, t+1}\left(C_{t+1}-h C_{t}\right)}
$$

where $P_{c, t}$ is the price of the overall consumption basket. The intra-temporal optimality condition is described by

$$
\frac{W_{t}}{P_{c, t}}=\nu_{t} N_{t}^{\varphi}\left(C_{t}-h C_{t-1}\right) \equiv M R S_{t}
$$

Following Blanchard and Gali (2007, 2010) and Blanchard and Riggi (2013), we formalize real wage rigidities by modifying the previous equation as

$$
\frac{W_{t}}{P_{c, t}}=\left\{\frac{W_{t-1}}{P_{c, t-1}}\right\}^{\gamma}\left\{M R S_{t}\right\}^{1-\gamma}
$$


where $\gamma$ is the degree of real wage rigidity. In the optimal allocation, we have

$$
P_{q, t} C_{q, t}=(1-\chi) P_{c, t} C_{t}
$$

and

$$
P_{m, t} C_{m, t}=\chi P_{c, t} C_{t}
$$

where $P_{c, t} \equiv P_{m, t}^{\chi} P_{q, t}^{1-\chi}$ and $P_{m, t}$ is the nominal price of oil. Also note $P_{c, t} \equiv P_{q, t} s_{t}^{\chi}$, where $s_{t} \equiv \frac{P_{m, t}}{P_{q, t}}$ is the real price of oil that follows an exogenous process given by

$$
\ln s_{t}=\rho_{s} \ln s_{t-1}+\epsilon_{s, t} .
$$

\subsubsection{Firms}

The representative final good firm produces homogenous good $Q_{t}$ by choosing a combination of intermediate inputs $Q_{t}(i)$ to maximize profit. Specifically, the problem of the final good firm is to solve:

$$
\max _{Q_{t}(i)} P_{q, t} Q_{t}-\int_{0}^{1} P_{q, t}(i) Q_{t}(i) d i
$$

subject to the CES production technology

$$
Q_{t}=\left[\int_{0}^{1} Q_{t}(i)^{\frac{\varepsilon-1}{\varepsilon}} d i\right]^{\frac{\varepsilon}{\varepsilon-1}}
$$

where $P_{q, t}(i)$ is the price of the intermediate good $i$ and $\varepsilon$ is the elasticity of substitution between intermediate goods. Then the final good firm's demand for intermediate good $i$ is given by

$$
Q_{t}(i)=\left(\frac{P_{q, t}(i)}{P_{q, t}}\right)^{-\varepsilon} Q_{t} .
$$

Substituting this demand for retail good $i$ into the CES bundler function gives

$$
P_{q, t}=\left[\int_{0}^{1} P_{q, t}(i)^{1-\varepsilon} d i\right]^{\frac{1}{1-\varepsilon}} .
$$

Intermediate goods are produced using labor, $N_{t}(i)$, and oil, $M_{t}(i)$, both supplied on perfectly competitive factor markets. Each firm $i$ produces according to the production function

$$
Q_{t}(i)=\left[A_{t} N_{t}(i)\right]^{1-\alpha} M_{t}(i)^{\alpha} \quad 0<\alpha<1
$$


where $\alpha$ is the share of oil in production and $A_{t}$ denotes non-stationary laboraugmenting technology

$$
\ln A_{t}=\ln \bar{g}+\ln A_{t-1}+\epsilon_{z, t} .
$$

Here, $\bar{g}$ is the steady-state gross rate of technological change and $\epsilon_{z, t}$ is $N\left(0, \sigma_{z}^{2}\right)$. Each intermediate good-producing firm's marginal cost is given by

$$
\psi_{t}(i)=\frac{W_{t}}{(1-\alpha) Q_{t}(i) / N_{t}(i)}=\frac{P_{m, t}}{\alpha Q_{t}(i) / M_{t}(i)}
$$

and the markup, $\mathcal{M}_{t}^{P}(i)$, equals

$$
\mathcal{M}_{t}^{P}(i)=\frac{P_{q, t}(i)}{\psi_{t}(i)}
$$

Given the production function, cost minimization implies that the firms' demand for oil is given by:

$$
M_{t}(i)=\frac{\alpha}{\mathcal{M}_{t}^{P}(i)} \frac{Q_{t}(i)}{s_{t}} \frac{P_{q, t}(i)}{P_{q, t}} .
$$

Letting $Q_{t}$ also denote aggregate gross output and defining $\Delta_{t} \equiv \int_{0}^{1}\left(\frac{P_{q, t}(i)}{P_{q, t}}\right)^{-\varepsilon} d i$ as the relative price dispersion measure, it follows that

$$
M_{t}=\frac{\alpha}{\mathcal{M}_{t}^{P}} \frac{Q_{t}}{s_{t}} \Delta_{t}^{\frac{\varepsilon-1}{\varepsilon}}
$$

where we have used the demand schedule faced by intermediate good firm $i$ and defined the average gross markup as $\mathcal{M}_{t}^{P} \equiv \int_{0}^{1} \mathcal{M}_{t}^{P}(i) d i$. Next combining the cost minimization conditions for oil and for labor with the aggregate production function yields the following factor price frontier:

$$
\left(\frac{W_{t}}{P_{c, t}}\right)^{1-\alpha} \mathcal{M}_{t}^{P}=\mathcal{C} A_{t}^{1-\alpha} s_{t}^{-\alpha-\chi(1-\alpha)} \Delta_{t}^{-\frac{1}{\varepsilon}}
$$

where $\mathcal{C} \equiv\left[\frac{1}{(1-\chi) \Theta_{\chi}}\left(\frac{1-\chi}{\chi}\right)^{\chi}\right]^{\alpha-1} \alpha^{\alpha}(1-\alpha)^{1-\alpha}$. The intermediate goods producers face a constant probability, $0<1-\xi<1$, of being able to adjust prices to a new optimal one, $P_{q, t}^{*}(i)$, in order to maximize expected discounted profits

$$
E_{t} \sum_{j=0}^{\infty} \xi^{j} \beta^{j} \frac{\lambda_{t+j}}{\lambda_{0}}\left[\frac{P_{q, t}^{*}(i)}{P_{q, t+j}} Q_{t+j}(i)-\frac{W_{t+j}}{(1-\alpha) P_{q, t+j} A_{t+j}^{1-\alpha}}\left\{\frac{(1-\alpha) P_{m, t+j}}{\alpha W_{t+j}}\right\}^{\alpha} Q_{t+j}(i)\right]
$$

subject to the constraint

$$
Q_{t+j}(i)=\left[\frac{P_{q, t}^{*}(i)}{P_{q, t+j}}\right]^{-\varepsilon} Q_{t+j}
$$


where

$$
\lambda_{t+j}=\frac{d_{t+j}}{P_{c, t+j}\left(C_{t+j}-h C_{t+j-1}\right)} .
$$

The first order condition for the optimized relative price $p_{q, t}^{*}(i) \equiv \frac{P_{q, t}^{*}(i)}{P_{q, t}}$ is given by

$$
p_{q, t}^{*}(i)=\frac{\varepsilon}{(\varepsilon-1)(1-\alpha)} \frac{E_{t} \sum_{j=0}^{\infty}(\xi \beta)^{j} \lambda_{t+j} \frac{W_{t+j}}{P_{q, t+j} A_{t+j}^{1-\alpha}}\left[\frac{(1-\alpha) P_{m, t+j}}{\alpha W_{t+j}}\right]^{\alpha}\left[\frac{P_{q, t}}{P_{q, t+j}}\right]^{-\varepsilon} Q_{t+j}}{E_{t} \sum_{j=0}^{\infty}(\xi \beta)^{j} \lambda_{t+j}\left[\frac{P_{q, t}}{P_{q, t+j}}\right]^{1-\varepsilon} Q_{t+j}} .
$$

The joint dynamics of the optimal reset price and inflation can be compactly described by rewriting the first-order condition for the optimal price in a recursive formulation as follows:

$$
p_{q, t}^{*}(i)=\frac{\varepsilon}{(\varepsilon-1)(1-\alpha)} \frac{\kappa_{t}}{\phi_{t}}
$$

where $\kappa_{t}$ and $\phi_{t}$ are auxiliary variables that allow one to rewrite the infinite sums that appear in the numerator and denominator of the above equation in recursive formulation:

$$
\kappa_{t}=\mathcal{C}\left(\frac{W_{t}}{P_{c, t}}\right)^{1-\alpha} s_{t}^{\chi(1-\alpha)+\alpha} A_{t}^{\alpha-1} Q_{t} \widetilde{\lambda}_{t}+\xi \beta\left[E_{t} \pi_{q, t+1}^{\varepsilon} \kappa_{t+1}\right]
$$

and

$$
\phi_{t}=Q_{t} \widetilde{\lambda_{t}}+\xi \beta\left[E_{t} \pi_{q, t+1}^{\varepsilon-1} \phi_{t+1}\right],
$$

where we have used the definition $\widetilde{\lambda_{t}}=\lambda_{t} P_{c, t}$. Note that $\kappa_{t}$ and $\phi_{t}$ can be interpreted as the present discounted value of marginal costs and marginal revenues respectively. Moreover, the aggregate price level evolves according to:

$$
\begin{aligned}
P_{q, t} & =\left[\int_{0}^{1} P_{q, t}(i)^{1-\varepsilon} d i\right]^{\frac{1}{1-\varepsilon}} \Rightarrow \\
1 & =\xi \pi_{q, t}^{\varepsilon-1}+(1-\xi) p_{q, t}^{*}(i)^{1-\varepsilon} \\
p_{q, t}^{*}(i) & =\left[\frac{1-\xi \pi_{q, t}^{\varepsilon-1}}{1-\xi}\right]^{\frac{1}{1-\varepsilon}} .
\end{aligned}
$$

\subsubsection{Definitions}

Production function is characterized by the following:

$$
Q_{t} \Delta_{t}=M_{t}^{\alpha}\left(A_{t} N_{t}\right)^{1-\alpha}
$$


The condition that trade be balanced gives us a relation between consumption and gross output:

$$
P_{c, t} C_{t}=\left(1-\frac{\alpha}{\mathcal{M}_{t}^{P}} \Delta_{t}^{\frac{\varepsilon-1}{\varepsilon}}\right) P_{q, t} Q_{t}
$$

The GDP deflator $P_{y, t}$ is implicitly defined by

$$
P_{q, t} \equiv\left(P_{y, t}\right)^{1-\alpha}\left(P_{m, t}\right)^{\alpha}
$$

Value added (or GDP) is then defined by

$$
P_{y, t} Y_{t}=\left(1-\frac{\alpha}{\mathcal{M}_{t}^{P}} \Delta_{t}^{\frac{\varepsilon-1}{\varepsilon}}\right) P_{q, t} Q_{t}
$$

Recall that price dispersion is defined as $\Delta_{t} \equiv \int_{0}^{1}\left(\frac{P_{q, t}(i)}{P_{q, t}}\right)^{-\varepsilon} d i$. Under the Calvo price mechanism, the above expression can be written recursively as:

$$
\Delta_{t}=(1-\xi) p_{q, t}^{*}(i)^{-\varepsilon}+\xi \pi_{q, t}^{\varepsilon} \Delta_{t-1}
$$

\subsubsection{Monetary policy}

Lastly, the model is closed by assuming that short-term nominal interest rate follows a feedback rule, of the type that has been found to provide a good description of actual monetary policy in the U.S. since Taylor (1993). Our specification of this policy rule features interest rate smoothing, a systematic response to deviations of inflation, output gap and output growth from their respective target values.

$R_{t}=\widetilde{R}_{t}^{1-\rho_{R}} R_{t-1}^{\rho_{R}} \exp \left\{\varepsilon_{R, t}\right\}, \quad \widetilde{R}_{t}=\bar{R}\left\{\left(\frac{\pi_{c, t}}{\bar{\pi}}\right)^{\tau}\left(\frac{\pi_{q, t}}{\bar{\pi}}\right)^{1-\tau}\right\}^{\psi_{\pi}}\left\{\frac{Y_{t}}{Y_{t}^{*}}\right\}^{\psi_{x}}\left\{\frac{Y_{t} / Y_{t-1}}{\bar{g}}\right\}^{\psi_{g}}$

where $\bar{\pi}$ denotes the central bank's inflation target (and is equal to the gross level of trend inflation), $\bar{R}$ is the gross steady-state policy rate, $\bar{x}$ is the steady state output gap, $\bar{g}$ is the gross steady state growth rate of the economy and $\varepsilon_{R, t}$ is an i.i.d. monetary policy shock. The output gap measures the deviation of the actual level of GDP $Y_{t}$ from the efficient level of GDP, i.e. the counterfactual level of GDP that would arise in the absence of monopolistic competition, nominal price stickiness and real wage rigidity, $Y_{t}^{*}$. The central bank responds to a convex combination of headline and core inflation (with the parameter $\tau$ governing the relative weights; setting $\tau$ to one implies that the central bank responds to headline inflation only). The coefficients 
$\psi_{\pi}, \psi_{x}$ and $\psi_{g}$ govern the central bank's responses to inflation, welfare-relevant output gap and output growth from their respective target values, and $\rho_{R} \in[0,1]$ is the degree of policy rate smoothing . 


\subsection{Tables}

Table A1: Parameter Estimates, Robustness (1966:I-1979:II)

\begin{tabular}{|c|c|c|c|c|c|}
\hline & JPT rule & Boundary & Output gap & Indexation & CoreCPI-Oil \\
\hline$\psi_{\pi}$ & $\begin{array}{l}1.31 \\
(0.17)\end{array}$ & $\begin{array}{l}1.34 \\
(0.37)\end{array}$ & $\begin{array}{l}1.44 \\
(0.15)\end{array}$ & $\begin{array}{l}1.38 \\
(0.15)\end{array}$ & $\begin{array}{l}1.37 \\
(0.27)\end{array}$ \\
\hline$\psi_{x}$ & $\begin{array}{l}0.08 \\
(0.08)\end{array}$ & $\begin{array}{l}0.04 \\
(0.03)\end{array}$ & $\begin{array}{l}0.13 \\
(0.11)\end{array}$ & $\begin{array}{l}0.05 \\
(0.04)\end{array}$ & $\begin{array}{l}0.05 \\
(0.08)\end{array}$ \\
\hline$\psi_{g}$ & $\begin{array}{l}0.50 \\
(0.18)\end{array}$ & $\begin{array}{l}0.30 \\
(0.15)\end{array}$ & $\begin{array}{l}0.40 \\
(0.15)\end{array}$ & $\begin{array}{l}0.31 \\
(0.13)\end{array}$ & $\begin{array}{l}0.43 \\
(0.18)\end{array}$ \\
\hline$\rho_{R}$ & $\begin{array}{l}0.64 \\
(0.06)\end{array}$ & $\begin{array}{l}0.66 \\
(0.07)\end{array}$ & $\begin{array}{l}0.69 \\
(0.05)\end{array}$ & $\begin{array}{l}0.68 \\
(0.06)\end{array}$ & $\begin{array}{l}0.69 \\
(0.05)\end{array}$ \\
\hline$\tau$ & $\begin{array}{l}0.77 \\
(0.12)\end{array}$ & $\begin{array}{l}0.55 \\
(0.15)\end{array}$ & $\begin{array}{l}0.47 \\
(0.17)\end{array}$ & $\begin{array}{l}0.58 \\
(0.15)\end{array}$ & $\begin{array}{l}0.38 \\
(0.15)\end{array}$ \\
\hline$\pi^{*}$ & $\begin{array}{l}1.37 \\
(0.21)\end{array}$ & $\begin{array}{l}1.34 \\
(0.18)\end{array}$ & $\begin{array}{l}1.38 \\
(0.16)\end{array}$ & $\begin{array}{l}1.37 \\
(0.19)\end{array}$ & $\begin{array}{l}1.47 \\
(0.20)\end{array}$ \\
\hline$R^{*}$ & $\begin{array}{l}1.57 \\
(0.21)\end{array}$ & $\begin{array}{l}1.50 \\
(0.20)\end{array}$ & $\begin{array}{l}1.53 \\
(0.19)\end{array}$ & $\begin{array}{l}1.53 \\
(0.21)\end{array}$ & $\begin{array}{l}1.65 \\
(0.20)\end{array}$ \\
\hline$g^{*}$ & $\begin{array}{l}0.47 \\
(0.07)\end{array}$ & $\begin{array}{l}0.46 \\
(0.07)\end{array}$ & $\begin{array}{l}0.44 \\
(0.07)\end{array}$ & $\begin{array}{l}0.45 \\
(0.07)\end{array}$ & $\begin{array}{l}0.43 \\
(0.08)\end{array}$ \\
\hline$\xi$ & $\begin{array}{l}0.62 \\
(0.03)\end{array}$ & $\begin{array}{l}0.59 \\
(0.04)\end{array}$ & $\begin{array}{l}0.60 \\
(0.04)\end{array}$ & $\begin{array}{l}0.59 \\
(0.04)\end{array}$ & $\begin{array}{l}0.64 \\
(0.04)\end{array}$ \\
\hline$\gamma$ & $\begin{array}{l}0.91 \\
(0.02)\end{array}$ & $\begin{array}{l}0.89 \\
(0.04)\end{array}$ & $\begin{array}{l}0.87 \\
(0.04)\end{array}$ & $\begin{array}{l}0.90 \\
(0.03)\end{array}$ & $\begin{array}{l}0.91 \\
(0.03)\end{array}$ \\
\hline$h$ & $\begin{array}{l}0.43 \\
(0.07)\end{array}$ & $\begin{array}{l}0.38 \\
(0.06)\end{array}$ & $\begin{array}{l}0.37 \\
(0.06)\end{array}$ & $\begin{array}{l}0.40 \\
(0.07)\end{array}$ & $\begin{array}{l}0.30 \\
(0.06)\end{array}$ \\
\hline$\omega$ & - & - & - & $\begin{array}{l}0.44 \\
(0.08)\end{array}$ & - \\
\hline$\rho_{d}$ & $\begin{array}{l}0.68 \\
(0.08)\end{array}$ & $\begin{array}{l}0.74 \\
(0.07)\end{array}$ & $\begin{array}{l}0.76 \\
(0.07)\end{array}$ & $\begin{array}{l}0.76 \\
(0.07)\end{array}$ & $\begin{array}{l}0.81 \\
(0.10)\end{array}$ \\
\hline$\rho_{\nu}$ & $\begin{array}{l}0.78 \\
(0.08)\end{array}$ & $\begin{array}{l}0.85 \\
(0.07)\end{array}$ & $\begin{array}{l}0.89 \\
(0.05)\end{array}$ & $\begin{array}{l}0.85 \\
(0.06)\end{array}$ & $\begin{array}{l}0.75 \\
(0.13)\end{array}$ \\
\hline$\sigma_{s}$ & $\begin{array}{c}17.33 \\
(1.64)\end{array}$ & $\begin{array}{l}17.04 \\
(1.54)\end{array}$ & $\begin{array}{l}17.25 \\
(1.61)\end{array}$ & $\underset{(1.56)}{17.22}$ & $\begin{array}{l}17.21 \\
(1.55)\end{array}$ \\
\hline$\sigma_{g}$ & $\begin{array}{l}0.51 \\
(0.09)\end{array}$ & $\begin{array}{l}0.50 \\
(0.09)\end{array}$ & $\begin{array}{l}0.49 \\
(0.08)\end{array}$ & $\begin{array}{l}0.45 \\
(0.08)\end{array}$ & $\begin{array}{l}0.56 \\
(0.09)\end{array}$ \\
\hline$\sigma_{r}$ & $\begin{array}{l}0.27 \\
(0.04)\end{array}$ & $\begin{array}{l}0.31 \\
(0.04)\end{array}$ & $\begin{array}{l}0.30 \\
(0.04)\end{array}$ & $\begin{array}{l}0.29 \\
(0.03)\end{array}$ & $\begin{array}{l}0.32 \\
(0.04)\end{array}$ \\
\hline$\sigma_{d}$ & $\begin{array}{l}2.10 \\
(0.33)\end{array}$ & $\begin{array}{l}1.60 \\
(0.44)\end{array}$ & $\begin{array}{l}1.68 \\
(0.30)\end{array}$ & $\begin{array}{l}1.97 \\
(0.35)\end{array}$ & $\begin{array}{l}2.07 \\
(0.37)\end{array}$ \\
\hline$\sigma_{\nu}$ & $\begin{array}{l}0.34 \\
(0.07)\end{array}$ & $\begin{array}{l}0.41 \\
(0.10)\end{array}$ & $\begin{array}{l}0.40 \\
(0.09)\end{array}$ & $\begin{array}{l}0.42 \\
(0.08)\end{array}$ & $\begin{array}{l}0.36 \\
(0.10)\end{array}$ \\
\hline$\sigma_{\zeta}$ & $\begin{array}{l}0.49 \\
(0.21)\end{array}$ & $\begin{array}{l}0.44 \\
(0.14)\end{array}$ & $\begin{array}{l}0.46 \\
(0.19)\end{array}$ & $\begin{array}{l}0.45 \\
(0.19)\end{array}$ & $\begin{array}{l}0.43 \\
(0.16)\end{array}$ \\
\hline$M_{s, \zeta}$ & $\begin{array}{l}0.05 \\
(0.94)\end{array}$ & $\begin{array}{l}0.16 \\
(0.83)\end{array}$ & $\begin{array}{l}-0.08 \\
(0.93)\end{array}$ & $\begin{array}{l}0.07 \\
(0.96)\end{array}$ & $\begin{array}{l}0.28 \\
(0.89)\end{array}$ \\
\hline$M_{g, \zeta}$ & $\begin{array}{l}-0.07 \\
(1.02)\end{array}$ & $\begin{array}{l}0.08 \\
(0.94)\end{array}$ & $\begin{array}{l}0.01 \\
(0.99)\end{array}$ & $\begin{array}{l}0.00 \\
(0.98)\end{array}$ & $\begin{array}{l}0.10 \\
(0.97)\end{array}$ \\
\hline$M_{r, \zeta}$ & $\begin{array}{l}0.06 \\
(0.98)\end{array}$ & $\begin{array}{c}-0.02 \\
(0.91)\end{array}$ & $\begin{array}{c}-0.01 \\
(0.96)\end{array}$ & $\begin{array}{l}0.00 \\
(0.97)\end{array}$ & $\begin{array}{c}-0.29 \\
(0.96)\end{array}$ \\
\hline$M_{d, \zeta}$ & $\begin{array}{l}0.00 \\
(0.98)\end{array}$ & $\begin{array}{l}0.12 \\
(0.94)\end{array}$ & $\begin{array}{l}0.16 \\
(1.04)\end{array}$ & $\begin{array}{l}0.07 \\
(1.00)\end{array}$ & $\begin{array}{l}0.19 \\
(0.99)\end{array}$ \\
\hline$M_{\nu, \zeta}$ & $\begin{array}{c}-0.15 \\
(1.01)\end{array}$ & $\begin{array}{l}0.02 \\
(0.94)\end{array}$ & $\begin{array}{c}-0.06 \\
(1.00)\end{array}$ & $\begin{array}{l}0.01 \\
(1.01)\end{array}$ & $\begin{array}{l}0.04 \\
(0.91)\end{array}$ \\
\hline$\lambda$ & $\begin{array}{l}1.00 \\
(0.25)\end{array}$ & $\begin{array}{l}1.09 \\
(0.25)\end{array}$ & $\begin{array}{l}1.08 \\
(0.22)\end{array}$ & $\begin{array}{l}1.09 \\
(0.21)\end{array}$ & $\begin{array}{l}0.97 \\
(0.28)\end{array}$ \\
\hline$\sigma_{w_{1}}$ & $\begin{array}{l}0.34 \\
(0.11)\end{array}$ & $\begin{array}{l}0.36 \\
(0.09)\end{array}$ & $\begin{array}{l}0.38 \\
(0.09)\end{array}$ & $\begin{array}{l}0.39 \\
(0.09)\end{array}$ & $\begin{array}{l}0.31 \\
(0.11)\end{array}$ \\
\hline$\sigma_{w_{2}}$ & $\begin{array}{l}0.51 \\
(0.09)\end{array}$ & $\begin{array}{l}0.42 \\
(0.11)\end{array}$ & $\begin{array}{l}0.43 \\
(0.10)\end{array}$ & $\begin{array}{l}0.44 \\
(0.09)\end{array}$ & $\begin{array}{l}0.51 \\
(0.10)\end{array}$ \\
\hline
\end{tabular}


Table A2: Parameter Estimates, Robustness (1984:I-2008:II)

\begin{tabular}{|c|c|c|c|c|c|}
\hline & JPT rule & Boundary & Output gap & Indexation & CoreCPI-Oil \\
\hline$\psi_{\pi}$ & $\begin{array}{l}2.92 \\
(0.29)\end{array}$ & $\begin{array}{l}2.95 \\
(0.30)\end{array}$ & $\begin{array}{l}2.16 \\
(0.21)\end{array}$ & $\begin{array}{l}3.06 \\
(0.33)\end{array}$ & $\begin{array}{l}2.86 \\
(0.35)\end{array}$ \\
\hline$\psi_{x}$ & $\begin{array}{l}0.29 \\
(0.13)\end{array}$ & $\begin{array}{l}0.11 \\
(0.05)\end{array}$ & $\begin{array}{l}0.13 \\
(0.10)\end{array}$ & $\begin{array}{l}0.17 \\
(0.08)\end{array}$ & $\begin{array}{l}0.07 \\
(0.04)\end{array}$ \\
\hline$\psi_{g}$ & $\begin{array}{l}0.58 \\
(0.16)\end{array}$ & $\begin{array}{l}0.61 \\
(0.13)\end{array}$ & $\begin{array}{l}0.58 \\
(0.14)\end{array}$ & $\begin{array}{l}0.51 \\
(0.12)\end{array}$ & $\begin{array}{l}0.60 \\
(0.13)\end{array}$ \\
\hline$\rho_{R}$ & $\begin{array}{l}0.62 \\
(0.06)\end{array}$ & $\begin{array}{l}0.71 \\
(0.04)\end{array}$ & $\begin{array}{l}0.72 \\
(0.04)\end{array}$ & $\begin{array}{l}0.70 \\
(0.04)\end{array}$ & $\begin{array}{l}0.74 \\
(0.04)\end{array}$ \\
\hline$\tau$ & $\begin{array}{l}0.19 \\
(0.08)\end{array}$ & $\begin{array}{l}0.13 \\
(0.05)\end{array}$ & $\begin{array}{l}0.20 \\
(0.07)\end{array}$ & $\begin{array}{l}0.12 \\
(0.05)\end{array}$ & $\begin{array}{l}0.16 \\
(0.07)\end{array}$ \\
\hline$\pi^{*}$ & $\begin{array}{l}0.96 \\
(0.10)\end{array}$ & $\begin{array}{l}0.94 \\
(0.09)\end{array}$ & $\begin{array}{l}0.94 \\
(0.07)\end{array}$ & $\begin{array}{l}0.94 \\
(0.09)\end{array}$ & $\begin{array}{l}0.96 \\
(0.09)\end{array}$ \\
\hline$R^{*}$ & $\begin{array}{l}1.48 \\
(0.15)\end{array}$ & $\begin{array}{l}1.43 \\
(0.14)\end{array}$ & $\begin{array}{l}1.44 \\
(0.14)\end{array}$ & $\begin{array}{l}1.47 \\
(0.14)\end{array}$ & $\begin{array}{l}1.46 \\
(0.14)\end{array}$ \\
\hline$g^{*}$ & $\begin{array}{l}0.22 \\
(0.05)\end{array}$ & $\begin{array}{l}0.18 \\
(0.04)\end{array}$ & $\begin{array}{l}0.14 \\
(0.04)\end{array}$ & $\begin{array}{l}0.18 \\
(0.05)\end{array}$ & $\begin{array}{l}0.15 \\
(0.05)\end{array}$ \\
\hline$\xi$ & $\begin{array}{l}0.68 \\
(0.03)\end{array}$ & $\begin{array}{l}0.61 \\
(0.05)\end{array}$ & $\begin{array}{l}0.67 \\
(0.04)\end{array}$ & $\begin{array}{l}0.51 \\
(0.05)\end{array}$ & $\begin{array}{l}0.64 \\
(0.04)\end{array}$ \\
\hline$\gamma$ & $\begin{array}{l}0.65 \\
(0.07)\end{array}$ & $\begin{array}{l}0.44 \\
(0.12)\end{array}$ & $\begin{array}{l}0.57 \\
(0.11)\end{array}$ & $\begin{array}{l}0.30 \\
(0.11)\end{array}$ & $\begin{array}{l}0.60 \\
(0.09)\end{array}$ \\
\hline$h$ & $\begin{array}{l}0.30 \\
(0.05)\end{array}$ & $\begin{array}{l}0.24 \\
(0.05)\end{array}$ & $\begin{array}{l}0.30 \\
(0.06)\end{array}$ & $\begin{array}{l}0.21 \\
(0.05)\end{array}$ & $\begin{array}{l}0.31 \\
(0.06)\end{array}$ \\
\hline$\omega$ & - & - & - & $\begin{array}{l}0.30 \\
(0.08)\end{array}$ & - \\
\hline$\rho_{d}$ & $\begin{array}{l}0.82 \\
(0.04)\end{array}$ & $\begin{array}{l}0.85 \\
(0.04)\end{array}$ & $\begin{array}{l}0.85 \\
(0.04)\end{array}$ & $\begin{array}{l}0.84 \\
(0.03)\end{array}$ & $\begin{array}{l}0.83 \\
(0.04)\end{array}$ \\
\hline$\rho_{\nu}$ & $\begin{array}{l}0.94 \\
(0.04)\end{array}$ & $\begin{array}{l}0.99 \\
(0.01)\end{array}$ & $\begin{array}{l}0.98 \\
(0.01)\end{array}$ & $\begin{array}{l}0.99 \\
(0.01)\end{array}$ & $\begin{array}{l}0.98 \\
(0.01)\end{array}$ \\
\hline$\sigma_{s}$ & $\begin{array}{l}14.86 \\
(1.03)\end{array}$ & $\begin{array}{l}14.92 \\
(1.06)\end{array}$ & $\begin{array}{l}14.98 \\
(1.05)\end{array}$ & $\begin{array}{l}14.81 \\
(0.99)\end{array}$ & $\begin{array}{l}12.76 \\
(0.87)\end{array}$ \\
\hline$\sigma_{g}$ & $\begin{array}{l}0.56 \\
(0.08)\end{array}$ & $\begin{array}{l}0.43 \\
(0.08)\end{array}$ & $\begin{array}{l}0.53 \\
(0.09)\end{array}$ & $\begin{array}{l}0.43 \\
(0.08)\end{array}$ & $\begin{array}{l}0.45 \\
(0.05)\end{array}$ \\
\hline$\sigma_{r}$ & $\begin{array}{l}0.14 \\
(0.01)\end{array}$ & $\begin{array}{l}0.18 \\
(0.02)\end{array}$ & $\begin{array}{l}0.17 \\
(0.02)\end{array}$ & $\begin{array}{l}0.18 \\
(0.02)\end{array}$ & $\begin{array}{l}0.17 \\
(0.02)\end{array}$ \\
\hline$\sigma_{d}$ & $\begin{array}{l}1.57 \\
(0.21)\end{array}$ & $\begin{array}{l}1.21 \\
(0.20)\end{array}$ & $\begin{array}{l}1.18 \\
(0.16)\end{array}$ & $\begin{array}{l}1.12 \\
(0.17)\end{array}$ & $\begin{array}{l}1.21 \\
(0.17)\end{array}$ \\
\hline$\sigma_{\nu}$ & $\begin{array}{l}0.44 \\
(0.08)\end{array}$ & $\begin{array}{l}0.78 \\
(0.16)\end{array}$ & $\begin{array}{l}0.70 \\
(0.13)\end{array}$ & $\begin{array}{l}0.92 \\
(0.14)\end{array}$ & $\begin{array}{l}0.62 \\
(0.12)\end{array}$ \\
\hline$\sigma_{\zeta}$ & $\begin{array}{l}0.42 \\
(0.14)\end{array}$ & $\begin{array}{l}0.53 \\
(0.25)\end{array}$ & $\begin{array}{l}0.44 \\
(0.17)\end{array}$ & $\begin{array}{l}0.43 \\
(0.15)\end{array}$ & $\begin{array}{l}0.48 \\
(0.17)\end{array}$ \\
\hline$M_{s, \zeta}$ & $\begin{array}{c}-0.18 \\
(0.98)\end{array}$ & $\begin{array}{l}0.08 \\
(0.98)\end{array}$ & $\begin{array}{c}-0.05 \\
(0.95)\end{array}$ & $\begin{array}{l}0.17 \\
(0.98)\end{array}$ & $\begin{array}{c}-0.15 \\
(0.98)\end{array}$ \\
\hline$M_{g, \zeta}$ & $\begin{array}{c}-0.07 \\
(0.94)\end{array}$ & $\begin{array}{l}0.01 \\
(0.94)\end{array}$ & $\begin{array}{c}-0.06 \\
(0.96)\end{array}$ & $\begin{array}{l}0.24 \\
(0.96)\end{array}$ & $\begin{array}{c}-0.01 \\
(0.99)\end{array}$ \\
\hline$M_{r, \zeta}$ & $\begin{array}{c}-0.17 \\
(0.95)\end{array}$ & $\begin{array}{c}-0.11 \\
(0.95)\end{array}$ & $\begin{array}{l}0.00 \\
(0.94)\end{array}$ & $\begin{array}{c}-0.34 \\
(0.96)\end{array}$ & $\begin{array}{c}-0.04 \\
(0.98)\end{array}$ \\
\hline$M_{d, \zeta}$ & $\begin{array}{l}0.07 \\
(0.99)\end{array}$ & $\begin{array}{l}0.20 \\
(0.98)\end{array}$ & $\begin{array}{l}0.04 \\
(0.93)\end{array}$ & $\begin{array}{c}-0.03 \\
(0.91)\end{array}$ & $\begin{array}{l}0.01 \\
(0.98)\end{array}$ \\
\hline$M_{\nu, \zeta}$ & $\begin{array}{l}0.13 \\
(0.97)\end{array}$ & $\begin{array}{c}-0.04 \\
(0.92)\end{array}$ & $\begin{array}{l}0.05 \\
(0.96)\end{array}$ & $\begin{array}{c}-0.05 \\
(0.99)\end{array}$ & $\begin{array}{c}-0.08 \\
(0.95)\end{array}$ \\
\hline$\lambda$ & $\begin{array}{l}0.15 \\
(0.09)\end{array}$ & $\begin{array}{l}0.29 \\
(0.08)\end{array}$ & $\begin{array}{l}0.31 \\
(0.08)\end{array}$ & $\begin{array}{l}0.30 \\
(0.07)\end{array}$ & $\begin{array}{l}0.33 \\
(0.10)\end{array}$ \\
\hline$\sigma_{w_{1}}$ & $\begin{array}{l}0.73 \\
(0.08)\end{array}$ & $\begin{array}{l}0.66 \\
(0.07)\end{array}$ & $\begin{array}{l}0.59 \\
(0.07)\end{array}$ & $\begin{array}{l}0.67 \\
(0.06)\end{array}$ & $\begin{array}{l}0.63 \\
(0.07)\end{array}$ \\
\hline$\sigma_{w_{2}}$ & $\begin{array}{l}0.42 \\
(0.04)\end{array}$ & $\begin{array}{l}0.38 \\
(0.04)\end{array}$ & $\begin{array}{l}0.36 \\
(0.03)\end{array}$ & $\begin{array}{l}0.38 \\
(0.04)\end{array}$ & $\begin{array}{l}0.37 \\
(0.04)\end{array}$ \\
\hline
\end{tabular}


Tables A1 and A2 report the posterior mean along with the standard deviations in parenthesis. 